\title{
The relative importance of competing pathways for the formation of high-molecular-weight peroxides in the ozonolysis of organic aerosol particles
}

\author{
M. Mochida ${ }^{1,2}$, Y. Katrib ${ }^{1}$, J. T. Jayne ${ }^{3}$, D. R. Worsnop ${ }^{3}$, and S. T. Martin ${ }^{1}$ \\ ${ }^{1}$ Division of Engineering and Applied Sciences, Harvard University, Cambridge, MA 02138, USA \\ ${ }^{2}$ Institute of Low Temperature Science, Hokkaido University, Sapporo, 060-0819, Japan \\ ${ }^{3}$ Aerodyne Research, Inc., Billerica, MA 08121, USA
}

Received: 29 May 2006 - Published in Atmos. Chem. Phys. Discuss.: 28 July 2006

Revised: 9 October 2006 - Accepted: 24 October 2006 - Published: 27 October 2006

\begin{abstract}
High-molecular-weight (HMW) organic compounds are an important component of atmospheric particles, although their origins, possibly including in situ formation pathways, remain incompletely understood. This study investigates the formation of HMW organic peroxides through reactions involving stabilized Criegee intermediates (SCI's). The model system is methyl oleate (MO) mixed with dioctyl adipate (DOA) and myristic acid (MA) in submicron aerosol particles, and Criegee intermediates are formed by the ozonolysis of the double bond in methyl oleate. An aerosol flow tube coupled to a quadrupole aerosol mass spectrometer (AMS) is employed to determine the relative importance of different HMW organic peroxides following the ozonolysis of different mixing mole fractions of MO in DOA and MA. Possible peroxide products include secondary ozonides (SOZ's), $\alpha$-acyloxyalkyl hydroperoxides and $\alpha$-acyloxyalkyl alkyl peroxides ( $\alpha$ AAHP-type compounds), diperoxides, and monoperoxide oligomers. Of these, the AMS data identify two SOZ's as major HMW products in the ozonolysis of pure methyl oleate as well as in an inert matrix of DOA to as low as 0.04 mole fraction MO. In comparison, in mixed particles of $\mathrm{MO}$ and $\mathrm{MA}$, $\alpha$ AAHP-type compounds form in high yields for MO mole fractions of 0.5 or less, suggesting that SCI's efficiently attack the carboxylic acid group of myristic acid. The reactions of SCI's with carboxylic acid groups to form $\alpha$ AAHP-type compounds therefore compete with those of SCI's with aldehydes to form SOZ's, provided that both types of functionalities are present at significant concentrations. The results therefore suggest that SCI's in atmospheric particles contribute to the transformation of carboxylic acids and other protic groups into HMW organic peroxides.
\end{abstract}

Correspondence to: S. T. Martin

(scot_martin@harvard.edu)

\section{Introduction}

Gas-phase ozonolysis of unsaturated organic molecules has been intensively investigated for decades (Atkinson and Arey, 2003). Ozonolysis is an important pathway for the degradation and the transformation of compounds in the atmosphere and is also a potential night-time source of radical species (Paulson and Orlando, 1996). Furthermore, some of the reactions yield products having sufficiently low vapor pressure to form secondary-organic-aerosol (SOA) particles (Griffin et al., 1999). There is limited knowledge, however, of the further chemical reactions inside the particle, although investigations of particle-phase ozonolysis have been accelerating recently (e.g., Rudich, 2003; Katrib et al., 2004; Ziemann, 2005). Ozonolysis reactions have been studied in depth by organic chemists for some time (Bailey, 1978), yet the reactions inside aerosol particles have important differences because of the mixture of components, the possible presence of water, and the coupling to the gas phase through evaporation and condensation. Ozonolysis of organic molecules inside particles can lead to the formation of increasingly polar compounds that alter physicochemical properties, such as particle hygroscopicity, $\mathrm{CCN}$ activity, and light scattering and extinction. The process by which these properties change during the residence time of a particle in the atmosphere is called "particle aging" (Kanakidou et al., 2005). In addition to reactions with ozone, particles also chemically age by reaction with hydroxyl radical (Bertram et al., 2001; Rudich, 2003; Eliason et al., 2004), nitrate radical (Hung et al., 2005; Docherty and Ziemann, 2006), and internally mixed chemical species, including acid-catalyzed and uncatalyzed pathways (Jang et al., 2002; Kalberer et al., 2004; Iinuma et al., 2004; Tolocka et al., 2004; Gao et al., 2004). Physical aging, such as the condensation of sulfuric acid or coagulation with inorganic particles, can also be an important mechanism in the atmosphere.

Published by Copernicus GmbH on behalf of the European Geosciences Union. 
A model system recently employed by numerous investigators in studies of particle aging is the ozonolysis of oleic acid in both pure and mixed systems. Ozonolysis reaction kinetics have been studied, including the gas-phase loss rate of ozone, the condensed-phase loss rate of the organic compound, and the effects of chemical mixtures, particle morphology, and physical state on those loss rates (Moise and Rudich, 2002; Morris et al., 2002; Smith et al., 2003; Thornberry and Abbatt, 2004; Hearn et al., 2005; Hearn and Smith, 2005; Katrib et al., 2005a, b; Knopf et al., 2005; Ziemann, 2005). Product identification and yields resulting from ozonolysis, as well as the associated reaction mechanisms, have been investigated (Katrib et al., 2004; Hearn and Smith, 2004; Zahardis et al., 2006a, b; Hung et al., 2005; Ziemann, 2005; Reynolds et al., 2006). Ozone-induced changes in particle properties, including hygroscopicity (Asad et al., 2004), CCN activity (Broekhuizen et al., 2004), and density (Katrib et al., 2005b), have been quantified.

Several of these studies suggest the occurrence of ozoneinduced oligomerization inside atmospheric aerosol particles as the ultimate fate of a portion of the stabilized Criegee intermediates (SCI's) (Hung et al., 2005; Zahardis et al., 2005, 2006a; Ziemann, 2005; Hearn et al., 2005; Reynolds et al., 2006). SCI's are primary products of the ozonolysis of unsaturated organic molecules. In situ oligomerization is one possible explanation for the large quantities of high-molecularweight (HMW) organic compounds that have recently been measured in atmospheric aerosol particles in urban and rural locations (Zappoli et al., 1999). To further assess the likelihood of ozone-induced oligomerization as an important source of HMW organic compounds in the atmosphere, the scientific community requires more quantitative information concerning the effects of several key differences between atmospheric processes and laboratory studies. Among other factors, these differences include the following:

1. The concentration of double bonds in particles of pure model compounds differs from that of atmospheric particles. This difference could affect the relative concentration of SCI's and thus the relative importance of competing pathways and product yields (including oligomerization) in a nonlinear kinetic system. Competing pathways identified in the ozonolysis of oleic acid include the formation of secondary ozonides (SOZ's as -C(OO)OC-, i.e., 1,2,4-trioxolanes) (Hung et al., 2005; Zahardis et al., 2005; Ziemann, 2005; Reynolds et al., 2006), $\alpha$-acyloxyalkyl hydroperoxides ( $\alpha$ AAHP-type compounds as - $\mathrm{C}(\mathrm{O}) \mathrm{OC}(\mathrm{OOH})$-, i.e., ester hydroperoxides) (Hung et al., 2005; Ziemann, 2005; Zahardis et al., 2005; Reynolds et al., 2006), and diperoxides (DP's as $-\mathrm{C}(\mathrm{OO})_{2} \mathrm{C}$-, i.e., 1,2,4,5-tetroxanes) (Zahardis et al., 2005; Reynolds et al., 2006), all of which form HMW organic peroxides. Monoperoxide oligomers of the type (-C-COOC-) are also possible (Nishikawa et al., 1995), although not observed by Reynolds et al. (2006). Ke- tones can also form by the reactions of SCI's with the double bond (Katrib et al., 2004; Hearn and Smith, 2004; Zahardis et al., 2006a, b). The suite of products therefore includes HMW peroxides as well as lowmolecular-weight (LMW) nonperoxidic aldehydes, carboxylic acids, and ketones.

2. In atmospheric particles, numerous oxygenated organic compounds may react with the SCI's, again affecting the relative importance of competing pathways, including oligomerization. These reactions imply the decomposition of saturated organic compounds and the formation of a variety of compounds, including other types of oligomers.

The present paper provides a report concerning the formation of HMW organic peroxides from the reactions of stabilized Criegee intermediates. Ozonolysis reactions are carried out for variable matrix substances and double-bond concentrations. The model system is methyl oleate (methyl 9octadecenoate) in mixed submicron aerosol particles. Unlike oleic acid, methyl oleate does not have a free carboxylic acid group, which when present can propagate polymerization in a myriad of pathways. Hence the reactions of methyl oleate are expected to be simpler than those of oleic acid, which aids greatly in sorting through the importance of competing pathways. Methyl oleate mixed at systematic mole fractions with nonreactive dioctyl adipate (DOA) is an approach for varying the concentration of double bonds. Similarly, methyl oleate mixed at systematic mole fractions with myristic acid (MA), which bears a reactive - $\mathrm{COOH}$ group, is an approach for investigating the reactivity of SCI's towards this pathway. Comparison of products formed for these different conditions is employed as the experimental strategy to elucidate the relative contribution of reaction pathways leading to the several classes of peroxides discussed above (i.e., SOZ's, $\alpha$ AAHP-type compounds, DP's, and possibly monoperoxide oligomers) as product pathways in the formation of HMW organic peroxides.

\section{Experimental procedures}

\subsection{Chemicals}

Aerosol particles of pure methyl oleate and mixtures of it with other organic solutes were generated by nebulizing solutions in organic solvents (HPLC-grade, TSI 3076 atomizer). To examine a possible influence of unevaporated solvent remaining in the aerosol particles, experiments were carried out in duplicate with ethyl acetate and methanol as solvents. Within experimental uncertainty, identical results were obtained in most experiments, and the few exceptions are discussed later in the text. The figures show data recorded from ethyl acetate solutions. Organic solutes used included methyl oleate (MO) (99\%), ethyl oleate (EO) (98\%), azelaic acid 
monomethyl ester (AAME) (85\%), dioctyl adipate (DOA) (bis(2-ethylhexyl) adipate, 99\%), and myristic acid (MA) (>99\%). These compounds were purchased from Aldrich.

\subsection{Instrumental setup}

A diagram of the experimental setup is presented in Fig. 1 . The aerosol passed through a diffusion charcoal scrubber and a bipolar charger. The aerosol flow was then introduced into a differential mobility analyzer (DMA) (TSI 3071A). 500-nm particles were classified (see Sect. 2.3). The particle loading ranged from 100 to $1000 \mu \mathrm{g} \mathrm{m}^{-3}$. The flow rates of the sample and sheath flows entering the DMA were 0.3 and $3 \mathrm{~L} \mathrm{~min}^{-1}$, respectively. The monodisperse aerosol flow was introduced to a flow tube reactor $(20-\mathrm{mm}$ inner diameter and $60-\mathrm{cm}$ length) at a rate of $0.15 \mathrm{~L} \mathrm{~min}^{-1}$ and $1 \mathrm{~atm}$. The remainder of the monodisperse aerosol was vented $\left(0.15 \mathrm{~L} \mathrm{~min}^{-1}\right.$ regulated by a critical orifice purchased from O'Keefe Controls Co.). The sheath flow of $0.75 \mathrm{~L} \mathrm{~min}^{-1}$ for the reactor was a dry $\mathrm{O}_{2} / \mathrm{N}_{2}$ mixture having 0 to $350 \mathrm{ppm} \mathrm{O}_{3}\left(0\right.$ to $\left.8.8 \times 10^{15} \mathrm{molec} \mathrm{cm}^{-3}\right)$. Ozone was generated in ultrapure air by ultraviolet irradiation from a low-pressure mercury lamp (Jelight Model 600). The calculated interaction time between the aerosol particles and the ozone for laminar flow was $6 \mathrm{~s}$ for a fully withdrawn injector, which was the geometry for most experiments described in this report. Compared to $6 \mathrm{~s}$, the interaction time of $0.25 \mathrm{~s}$ for ozone with the particles in the connection between the flow tube and the AMS was brief. The effective mixing time (ca. $0.35 \mathrm{~s}$ ) of ozone with the aerosol at the inlet of the flow tube was also short (Morris et al., 2002). Experiments were at room temperature and $0 \%$ relative humidity. The integrated number concentration was measured with a Condensation Particle Counter (TSI 3022A, 0.30 $\mathrm{L} \mathrm{min}^{-1}$ ). Alternatively, a Scanning Mobility Particle Sizer (SMPS) (TSI 3936, $0.30 \mathrm{~L} \mathrm{~min}^{-1}$ ) was used for mobility diameter measurements. The sheath flow in the tube reactor was regulated using a critical orifice $\left(0.52 \mathrm{~L} \mathrm{~min}^{-1}\right)$.

The chemical composition of the aerosol particles was analyzed using an electron-impact quadrupole aerosol mass spectrometer (Q-AMS, $0.08 \mathrm{~L} \mathrm{~min}^{-1}$ ) (Aerodyne Research, Inc.). Three different operating modes of the AMS were employed during the experiments, namely the mass spectrum (MS) scanning mode, the particle time-of-flight (TOF) mode, and the jump mass spectrum (JMS) mode (Jayne et al., 2000; Jimenez et al., 2003). The MS mode was used to obtain mass spectra from $\mathrm{m} / \mathrm{z} 0$ to 390 , where $\mathrm{m} / \mathrm{z}$ denotes the mass-tocharge ratio of the fragment. The TOF mode was used to measure the vacuum aerodynamic diameter $\left(d_{v a}\right)$ of particles. The JMS mode provided increased analytical sensitivity for monitoring intensities of high-mass ions $(\mathrm{m} / \mathrm{z}>202)$.
Table 1. Mobility diameter ( $\mathrm{nm}$ ) for increasing reaction time. Mobility diameters at 0 and 6 are estimated from measurements of the vacuum aerodynamic diameters (within parentheses) by the AMS and use of the relationship $d_{m}=\left(\rho_{0} / \rho_{\mathrm{MO}}\right) d_{v a}$, whereas mobility diameters at 27 and $45 \mathrm{~s}$ are measured by the SMPS. Average values of three experiments, which agree within $1 \mathrm{~nm}$, are shown for pure MO particles exposed to no ozone and for particles composed of products after complete MO ozonolysis. In the absence of ozone, the particle diameter decreases because of evaporation of MO. In the presence of ozone, MO is entirely ozonized by 27 s so that the diameter decreases recorded at 27 and $45 \mathrm{~s}$ arise from the evapora-

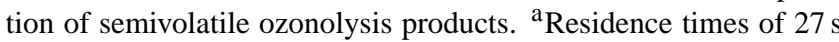
or $45 \mathrm{~s}$ are based upon $6 \mathrm{~s}$ in the flow tube, 2 or $20 \mathrm{~s}$ in short or long pieces of tubing between the flow tube and the DMA, $5 \mathrm{~s}$ in the DMA inlet, and an effective $14 \mathrm{~s}$ within the electric field of the DMA. The actual residence time within the electric field is approximately $28 \mathrm{~s}$, yet the particles are evaporating during this time so that the measured effective mobility diameter is a convolution of the entering and exiting diameters and the flow field within the DMA. We estimate that this temporal mean diameter corresponds to one-half the residence time (14s).

\begin{tabular}{ccccc}
\hline & \multicolumn{4}{c}{ Time (s) } \\
\hline & 0 & 6 & $27^{\mathrm{a}}$ & $45^{\mathrm{a}}$ \\
\hline no ozone exposure & 500 & 477 & 425 & 356 \\
& $(437)$ & $(417)$ & $(-)$ & $(-)$ \\
ozone exposure of $5 \times 10^{-5} \mathrm{~atm} \mathrm{O}_{3}$ & - & - & 438 & 434 \\
& $(-)$ & $(446)$ & $(-)$ & $(-)$ \\
\hline
\end{tabular}

\subsection{Determination of aerosol particle size}

In the absence of $\mathrm{O}_{3}$, the diameter of $\mathrm{MO}$ particles decreased by ca. $4 \mathrm{~nm} \mathrm{~s}^{-1}$ because of evaporation in the flow tube. The evaporation rate was determined by the following procedure. (1) The injector was fully inserted into the flow tube so that the outlet of the injector met the flow tube outlet, thus giving an interaction time with ozone of nominally $0 \mathrm{~s}$. The DMA voltage was adjusted to a mobility diameter $\left(d_{m}\right)$ of $500 \mathrm{~nm}$. The volume-equivalent diameter equaled the mobility diameter because $\mathrm{MO}$ was liquid at room temperature and because the aerosol particles were therefore nonporous and spherical. When the injector was fully withdrawn so that the interaction time of the particles with ozone in the flow tube was $6 \mathrm{~s}$, a decrease in $d_{v a}$ of approximately $20 \mathrm{~nm}$ was observed as a result of evaporation (Table 1). The $d_{m}$ values of 500 and $477 \mathrm{~nm}$ at 0 and $6 \mathrm{~s}$ injector positions, respectively, were calculated from the relationship of $d_{m}=\left(\rho_{0} / \rho_{M O}\right) d_{v a}$ (DeCarlo et al., 2004; Katrib et al., 2004b), where the densities $\rho_{M O}$ and $\rho_{0}$ were 0.874 and $1.000 \mathrm{~g} \mathrm{~cm}^{-3}$, respectively. The mass spectra verified that no changes in particle composition occurred for different injector positions, as expected.

In addition to evaporation, particle aerodynamic diameter also changed by the addition of $\mathrm{O}_{3}$ to the flow. Factors 


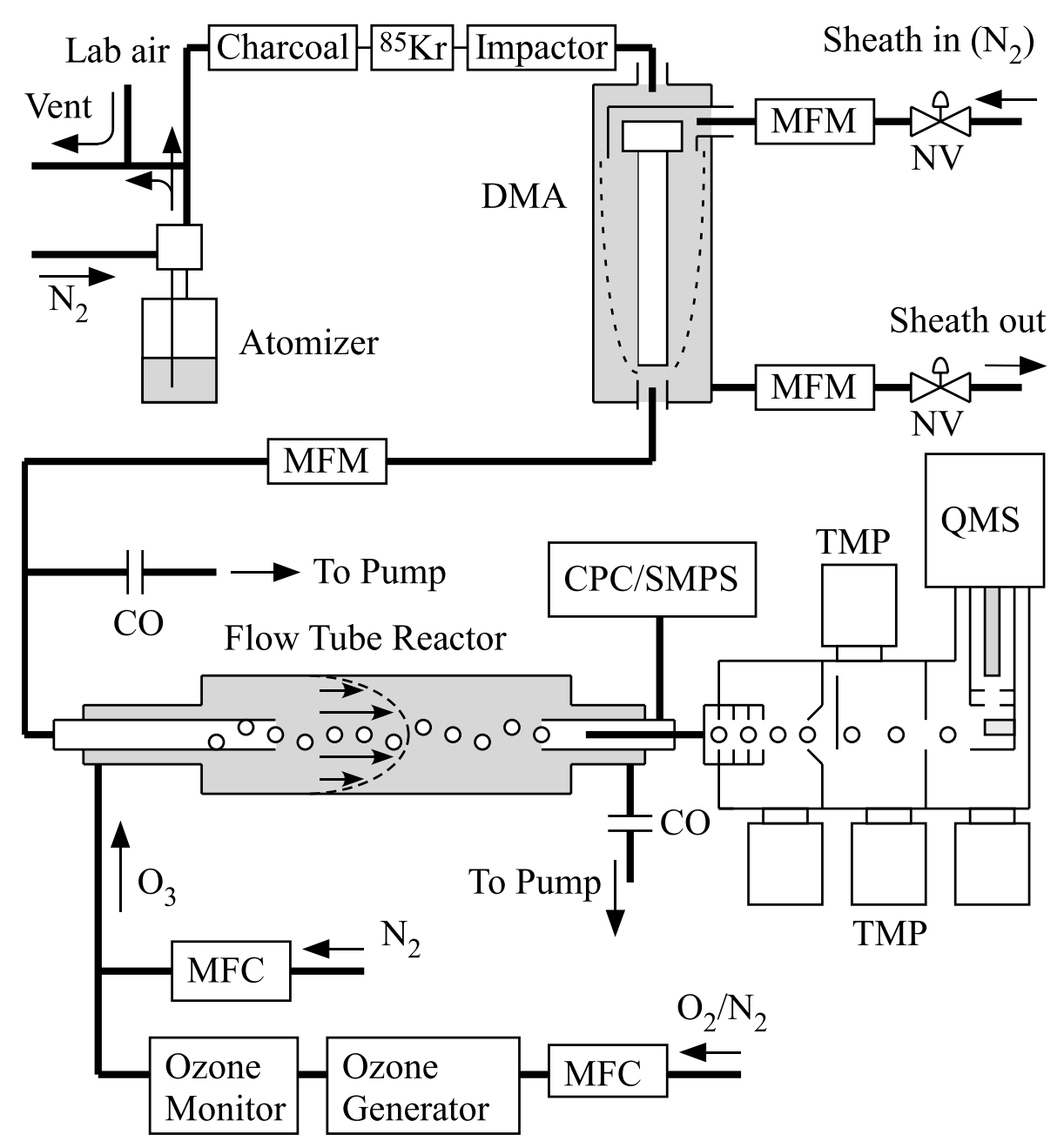

Fig. 1. Schematic diagram of the experimental setup. Key: DMA, differential mobility analyzer; CPC, condensation particle counter; SMPS, scanning mobility particle sizer; TMP, turbo molecular pump; QMS, quadrupole mass spectrometer; MFC, mass flow controller; MFM, mass flow meter; $\mathrm{CO}$, critical orifice; $\mathrm{NV}$, needle valve.

contributing to the change in diameter included (1) the reactive uptake of $\mathrm{O}_{3}$ by particles (i.e., increasing particle mass by adding oxygen atoms to molecules), (2) increases or decreases in the particle density due to alterations of the chemical composition, (3) the suppression of MO evaporation as a result of MO consumption during ozonolysis, and (4) the formation and the evaporation of volatile products such as nonanal. As shown in Table $1, d_{v a}$ of particles after the ozonolysis was $446 \mathrm{~nm}$ for an ozone exposure $P_{\mathrm{O} 3} \times t$ of $3 \times 10^{-4}$ atm s, where $P_{\mathrm{O} 3}$ and $t$ are the partial pressure of $\mathrm{O}_{3}$ and the interaction time in the flow tube, respectively. In a separate measurement (see also Sect. 3.2), $d_{m}$ of $438 \mathrm{~nm}$ for the reacted particles was measured, from which a density of $1.02 \mathrm{~g} \mathrm{~cm}^{-3}$ was calculated by $\rho=\rho_{0} d_{v a} / d_{m}$ (DeCarlo et al., 2004).

For the organic compounds used in the mixed particle experiments, control studies employing pure particles showed that MA (ca. $1 \mathrm{~nm} \mathrm{~s}^{-1}$ ), AAME (ca. $3 \mathrm{~nm} \mathrm{~s}^{-1}$ ), and EO (ca. $2 \mathrm{~nm} \mathrm{~s}^{-1}$ ) also evaporated in the flow tube. No evaporation of DOA was detected.

\subsection{Mole fraction of methyl oleate in mixed particles}

Prior to the ozonolysis of particles of MO mixed with a matrix substance such as DOA or MA, the mole fraction of methyl oleate $\left(x_{\mathrm{MO}}\right)$ was determined, as follows. The weight percent of $\mathrm{MO}\left(w_{\mathrm{MO}}\right)$ was related to the relative contribution of $m / z 296$ of the MO molecular ion to the mass spectrum, as follows:

$$
w_{\mathrm{MO}}=\frac{100 R I E_{\text {matrix }}\left(I_{\text {mix }}^{296} / \sum_{m / z} I_{\text {mix }}^{m / z}\right)}{R I E_{\mathrm{MO}}\left(I_{\mathrm{MO}}^{296} / \sum_{m / z} I_{\mathrm{MO}}^{m / z}\right)+\left(R I E_{\text {matrix }}-R I E_{\mathrm{MO}}\right)\left(I_{\text {mix }}^{296} / \sum_{m / z} I_{\text {mix }}^{m / z}\right)}
$$

where $R I E_{\mathrm{MO}}$ and $R I E_{\mathrm{matrix}}$ are the ionization efficiencies of $\mathrm{MO}$ and of the matrix substance, respectively, relative to nitrate as ammonium nitrate (Jayne et al., 2000). The 


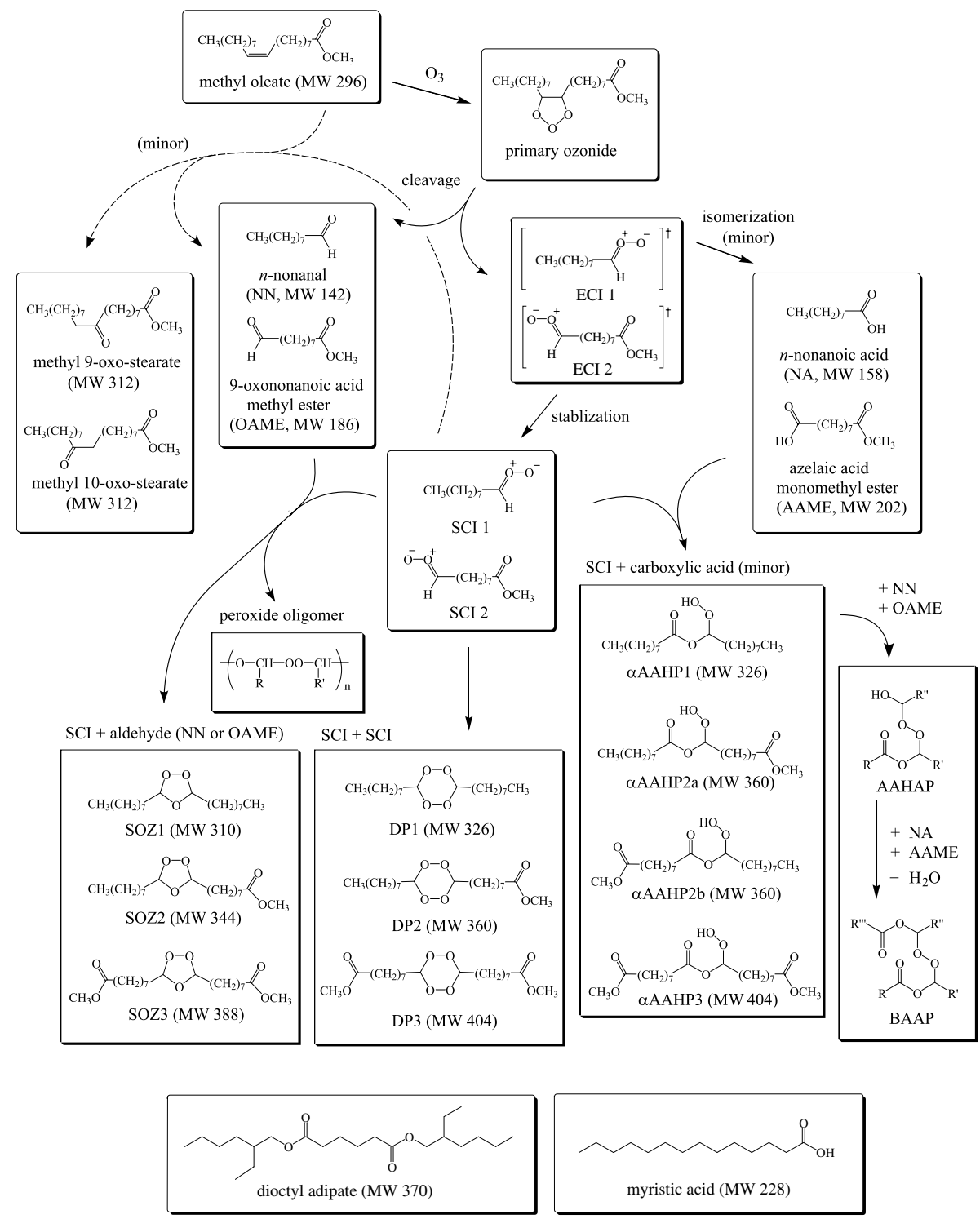

Fig. 2. Proposed reaction pathways for the ozonolysis of pure methyl oleate. Formation pathways of HMW organic peroxides are shown, including secondary ozonides (SOZ's), $\alpha$-acyloxyalkyl peroxides ( $\alpha$ AAHP's), diperoxides, and monoperoxide oligomers. Stereoisomers are not presented separately. The reaction mechanism follows that introduced by Ziemann (2005) (solid arrows) for the ozonolysis of oleic acid and that recently suggested by Zahardis et al. (2006b) (dashed arrows) for the ozonolysis of methyl oleate. For reference, the figure also shows the structures of the matrix substances DOA and MA. Dilution of MO in DOA or MA affects the relative contribution of the each pathway to the product yields.

derivation of Eq. (1) is provided in the appendix. The RIE values were determined using particles of pure compounds. The measurements were made at the 6-s injector position, thereby including the effect of volatilization in the flow tube. In Eq. (1), $I_{\mathrm{MO}}^{296}$ and $I_{\mathrm{mix}}^{296}$ are the $\mathrm{m} / \mathrm{z}, 296$ intensities recorded for pure $\mathrm{MO}$ and mixed $\mathrm{MO} /$ matrix particles, respectively. $\Sigma I_{\mathrm{MO}}^{m / z}$ and $\Sigma I_{\text {mix }}^{m / z}$ denote intensity sums for $m / z 0$ to 390 , omitting $m / z$ values of air beams (e.g., $m / z$ 28). The matrix substances were verified to have negligible intensity at $\mathrm{m} / \mathrm{z}$ 296.
The mole fraction of MO $\left(x_{\mathrm{MO}}\right)$ was calculated from its weight percent, as follows:

$x_{\mathrm{MO}}=\frac{w_{\mathrm{MO}}}{M W_{\mathrm{MO}}} /\left(\frac{w_{\mathrm{MO}}}{M W_{\mathrm{MO}}}+\frac{100-w_{\mathrm{MO}}}{M W_{\text {matrix }}}\right)$

where $M W_{\mathrm{MO}}$ and $M W_{\text {matrix }}$ were the molecular weights of $\mathrm{MO}$ and the matrix substance, respectively. The mole fractions determined by Eq. (2) differed by up to $50 \%$ from those of the reservoir solutions used in nebulization, presumably because of different evaporation rates of $\mathrm{MO}$ and the matrix substances in the scrubber and elsewhere in the apparatus. 


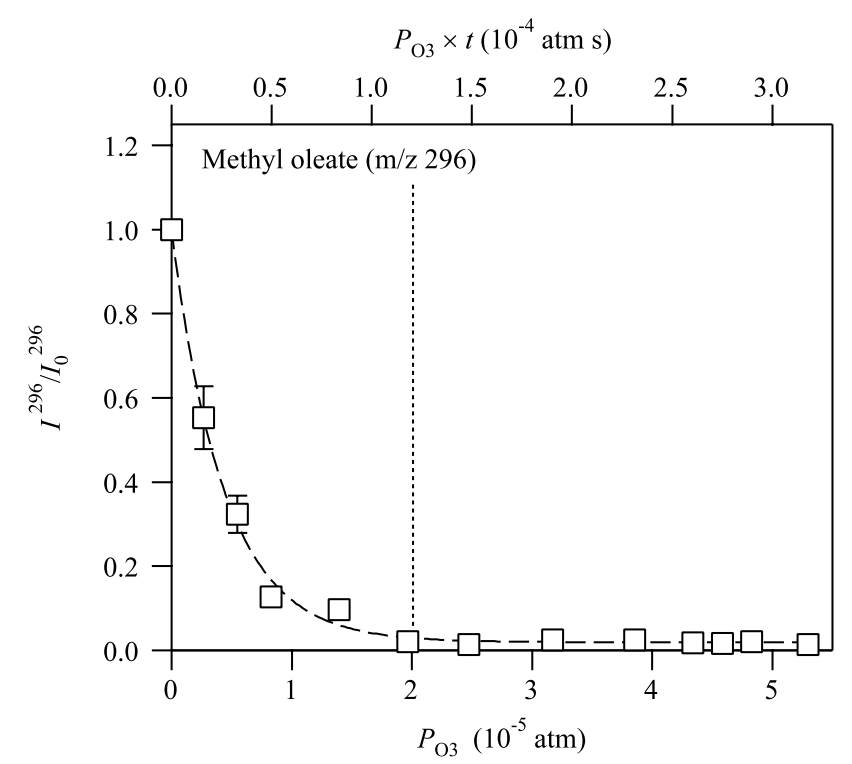

Fig. 3. Loss of methyl oleate for increasing ozone partial pressure. The signal intensities at $\mathrm{m} / \mathrm{z}, 296$ are normalized to the intensity prior to ozonolysis. The $\mathrm{O}_{3}$ concentration for which methyl oleate reacts to near completion is shown by the vertical dashed line. The particle mobility diameter prior to ozonolysis is $500 \mathrm{~nm}$. The exposure time is $6 \mathrm{~s}$. The reaction is at room temperature and $0 \%$ relative humidity.

\section{Results and discussion}

Reaction pathways of the ozonolysis of pure MO particles (Fig. 2) have similarities with those of pure oleic acid particles (Ziemann, 2005), although several of the pathways for polymerization are absent (Hung et al., 2005). Methyl oleate reacts with $\mathrm{O}_{3}$ diffusing into the particles and forms a primary ozonide (1,2,3-trioxolane). Because this primary ozonide is unstable, it readily decomposes and forms Criegee intermediates (CI) and aldehydes. In one reaction pathway, the Cl's isomerize to form carboxylic acids, including $n$-nonanoic acid (NA) and azelaic acid monomethyl ester (AAME; 9-methoxy-9-oxo-nonanoic acid). The CI's may also relax from their high vibrational states to form SCI's. For reasons outlined in Sect. 3.4, the evidence indicates that relaxation to form SCI's, rather than isomerization to NA or AAME, is the dominant fate of the CI's.

The SCI's can react by several pathways to lead to molecules of MW greater than that of MO. Reaction mechanisms are presented in Fig. 2. Peroxides can form by the reaction of an SCI with aldehydes or carboxylic acids or with another SCI, all of which are products of MO ozonolysis. SCI's react with aldehydes to form SOZ's (SOZ1 to 3) or monoperoxide oligomers (-C-COOC-). The self-reactions of SCI's form diperoxides (DP1 to 3) (Zahardis et al., 2005). SCI's also react with protic or nucleophilic molecules to form hydroperoxides, in particular $\alpha$-acyoxyalkyl hydroperoxide products ( $\alpha$ AAHP1, 2a, 2b, and 3 ) through the reactions of the SCI's with the carboxylic acids formed as first-generation products in MO ozonolysis. The hydroperoxides can react further with aldehydes to form $\alpha$-acyloxyalkyl hydroxyalkyl peroxides (AAHAP's), which have MW's greater than those of the $\alpha$ AAHP's. Rebrovic (1992) proposes that AAHAP's can continue to react with carboxylic acids to lose water and form bis(acyloxy-1-alkyl) peroxides (BAAP's). Although Nishikawa et al. (1995) suggest that terminal AAHAP products are more favored than BAAP's, Ziemann (2005) reports BAAP's as products in the ozonolysis of oleic acid aerosol particles. $\alpha$ AAHP, AAHAP, and BAAP compounds are hereafter grouped together under the label " $\alpha$ AAHP-type compounds." A nonperoxidic pathway to increase MW by one oxygen atom is ketone formation by the reaction of SCI's with double bonds in the ozonolyses of unsaturated fatty acids and their methyl esters (Katrib et al., 2004; Hearn and Smith, 2004; Zahardis et al., 2006a, b), thereby forming methyl 9-oxo- and 10-oxo-stearates from MO.

The products can be categorized as having low or high MW's based on the highest molecular weight expected by the products of primary ozonolysis, namely $\mathrm{m} / \mathrm{z} 202$ of azeleic acid monomethyl ester. LMW products therefore include $n$-nonanal (NN), 9-oxononanoic acid monomethyl ester (OAME; methyl 9-oxo-nonanoate), $n$-nonanoic acid, and azelaic acid monomethyl ester. HMW peroxide products composed of these molecules as subunits include SOZ's, $\alpha$ AAHP-type compounds, DP's, and monoperoxide oligomers. The SCI-induced ketone products, such as the methyl oxo-stearate, are also HMW products.

In the following sections, we present results on the ozonolysis and loss of methyl oleate in pure particles (Sect. 3.1), on the effects of ozonolysis on the rates of particle evaporation (Sect. 3.2), on the connections between evaporation and the formation of HMW products (also Sect. 3.2), and on the relative importance in mixed particles of the competing peroxide pathways (Sects. 3.3 to 3.5). Relative importance is assessed by comparing product yields across a suite of experiments in which methyl oleate is mixed at systematic mole fractions with dioctyl adipate (DOA) and myristic acid (MA). Section 3.6 addresses the relative rates of the competing pathways.

\subsection{Ozonolysis and loss of methyl oleate}

Figure 3 shows the decrease in the concentration of methyl oleate $(\mathrm{m} / \mathrm{z}$ 296) when pure MO aerosol particles are exposed to increasing $\mathrm{O}_{3}$. For an $\mathrm{O}_{3}$ exposure above $1.2 \times 10^{-4} \mathrm{~atm} \mathrm{~s}^{-1}$, MO disappears nearly completely. The slope of the initial decay in Fig. 3 (i.e., $I^{296} / I_{0}^{296}>0.5$ ) yields an upper limit of $1.1 \pm 0.2 \times 10^{-3}$ for the reactive uptake coefficient by assuming that the loss of one $\mathrm{MO}$ molecule implies the reaction of one $\mathrm{O}_{3}$ molecule (Katrib et al., 2005b). This value is consistent with a literature value of $1.23 \pm 0.10 \times 10^{-3}$ (Hearn et al., 2005). A more detailed kinetic mechanism of $\mathrm{O}_{3}$ loss (e.g., concerning the 
reacto-diffusive length of $\mathrm{O}_{3}$ in the particles) is not assessed in this study.

The mass spectra recorded for pure MO aerosol particles prior to ozonolysis, as well as those of the particle-phase products after ozonolysis, are shown in Fig. 4. Methyl oleate has characteristic peaks for the parent ion $[\mathrm{MO}]^{+}$at $\mathrm{m} / \mathrm{z} 296$ and for the fragment ions at $m / z 222$ and 264 (Fig. 4a). The peak at $m / z, 264$ corresponds to $[\mathrm{MO}-32]^{+}$, which is the ion formed by the removal of methanol from the methyl ester group. The $[\mathrm{MO}-74]^{+}$ion at $m / z, 222$ results from a loss of $\mathrm{CH}_{2}=\mathrm{C}(\mathrm{OH}) \mathrm{OCH}_{3}$ via McLafferty rearrangement of the methyl ester group in the molecule (McLafferty and Tureček, 1993). The intensities at $\mathrm{m} / \mathrm{z} 222,264$, and 296 decrease and eventually disappear for increasing $\mathrm{O}_{3}$ exposure (data not shown). Concomitantly, the intensities of the product peaks increase, notably at $m / z 141,143,152,155,171$, and 185 (Fig. 4b). In addition, small but non-negligible peaks at $\mathrm{m} / \mathrm{z}$ $279,291,311,323$, and 355 are present above $m / z$ 202, and the associated peak intensities are reproducible in several experiments on different days (one sigma variation of $16 \%$ ). These peaks are not attributable to MO fragmentation. The data in Fig. 4b therefore implicate the presence of ozonolysis products having molecular weights greater than 202 (see Sect. 3.3).

3.2 Decreased rates of particle evaporation: connections to the formation of high-molecular-weight products

In addition to the mass spectral evidence of Sect. 3.1, the formation of HMW products can also be inferred from the relative evaporation rates of reacted and unreacted aerosol particles. Prior to ozonolysis, MO particles evaporate at a rate of $4 \mathrm{nms}^{-1}$ (Table 1). In comparison, by changing the residence time of particles between the flow tube and the SMPS, we determine that the evaporation rate of ozone-reacted particles is $0.15 \mathrm{~nm} \mathrm{~s}^{-1}$, as given by $(434 \mathrm{~nm}-$ $438 \mathrm{~nm}) /(45 \mathrm{~s}-27 \mathrm{~s})$. This evaporation rate is measured after complete $\mathrm{MO}$ reaction, implying that the evaporating species are semivolatile reaction products. This evaporation rate is twenty times slower than that of AAME $\left(3 \mathrm{~nm} \mathrm{~s}^{-1}\right)$, which, as a diacid compared to NN, NA, and OAME, is the LMW product having the lowest expected volatility and hence the slowest rate of evaporation. The possible explanation that the slow evaporation rates result from decreased thermodynamic activities (i.e., vapor pressures) in a mixed solvent appears insufficient to explain the large magnitude of the reduced rate of evaporation. The evaporation rate of $0.15 \mathrm{~nm} \mathrm{~s}^{-1}$ therefore implies significant inhibition of evaporation, which can be explained by the formation of HMW products having very low vapor pressures. A related inference is that the sum of the volume fractions of the four LMW products in the particles has an upper limit of approximately $5 \%$ (i.e., $\left.100\left(0.15 \mathrm{~nm} \mathrm{~s}^{-1}\right) /\left(3 \mathrm{~nm} \mathrm{~s}^{-1}\right)\right)$. This conclusion of $5 \%$ follows from assumptions that the evaporation rates of LMW products are proportional to their volume fractions and that

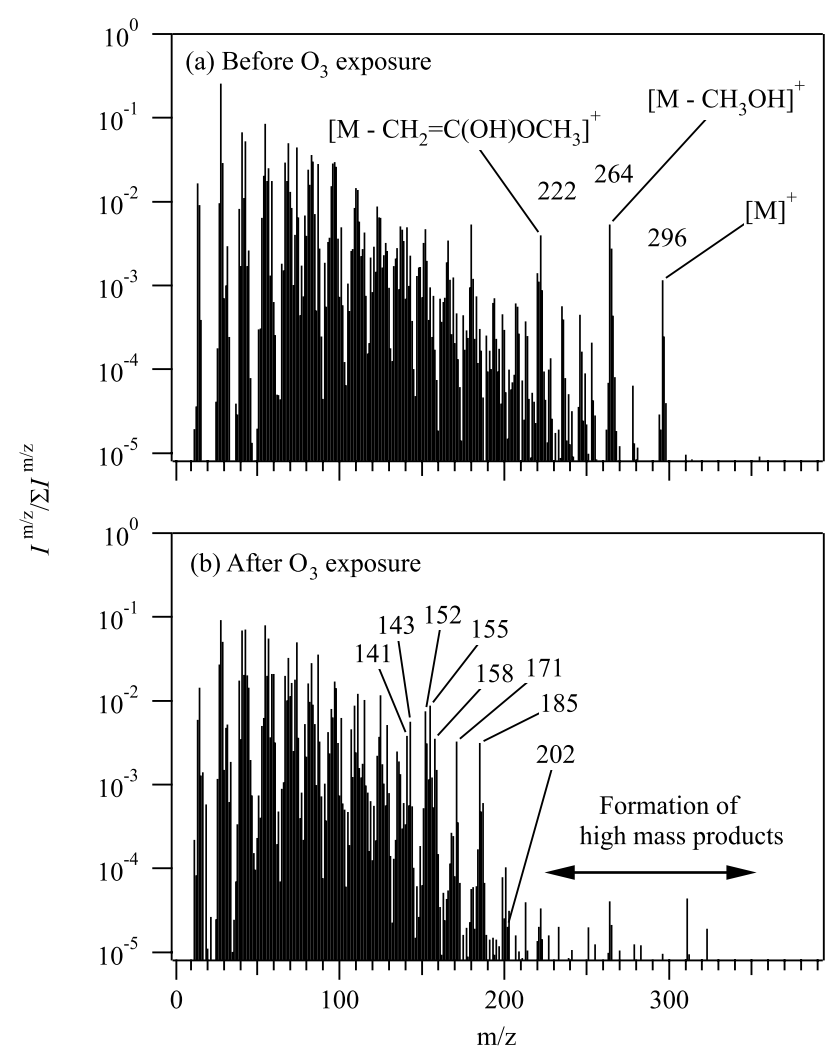

Fig. 4. Mass spectra of methyl oleate aerosol particles (a) before and (b) after ozone exposure. The particle mobility diameter prior to ozonolysis is $500 \mathrm{~nm}$. The $\mathrm{O}_{3}$ exposure is $5 \times 10^{-5}$ atm for $6 \mathrm{~s}$. $I^{m / z}$ is the intensity recorded when tuned to $m / z$, and $\Sigma I^{m / z}$ denotes the intensity sum for $m / z$ to 390 , omitting $\mathrm{m} / \mathrm{z}$ values of air beams (e.g., $m / z, 28)$.

AAME sets the lower limit for the volatility of the LMW products (i.e., corresponding to $3 \mathrm{~nm} \mathrm{~s}^{-1}$ ).

Further analysis suggests that more than $60 \mathrm{wt} \%$ of the ozonolysis products have high molecular weights, as follows. The mass $m_{p}$ of a spherical particle can be calculated by $m_{p}=(\pi / 6) d_{m}^{3} \rho$ and $\rho=\rho_{0} d_{v a} / d_{m}$ (Katrib et al., 2005b). The ratio of particle mass before and after the $\mathrm{O}_{3}$ exposure is then 0.78 , according to the data shown in Table 1 for 0 and $6 \mathrm{~s}$. In this calculation, the density of products is $1.02 \mathrm{~g} \mathrm{~cm}^{-3}$ by use of by $\rho=\rho_{0} d_{v a} / d_{m}$, for which $d_{m}$ at $27 \mathrm{~s}$ is assumed to have the same value as at $6 \mathrm{~s}$. This approximation is accurate because the rate of evaporation of MO ozonolysis products between the flow tube (6s) and the SMPS (27s) is low (i.e., as observed between 27 and $45 \mathrm{~s}\left(0.15 \mathrm{~nm} \mathrm{~s}^{-1}\right)$ ). For comparison, by similar analysis, Katrib et al. (2005b) report that the density of products from oleic acid ozonolysis is $1.05 \mathrm{~g} \mathrm{~cm}^{-3}$. The mass ratio of 0.78 can be compared to the expected ratio of 1.16 arising from the stoichiometric addition of ozone in the absence of the volatilization of $\mathrm{MO}$ or the reaction products. MO volatilization is negligible because of complete reaction within $2 \mathrm{~s}$ based upon the reaction kinetics. 


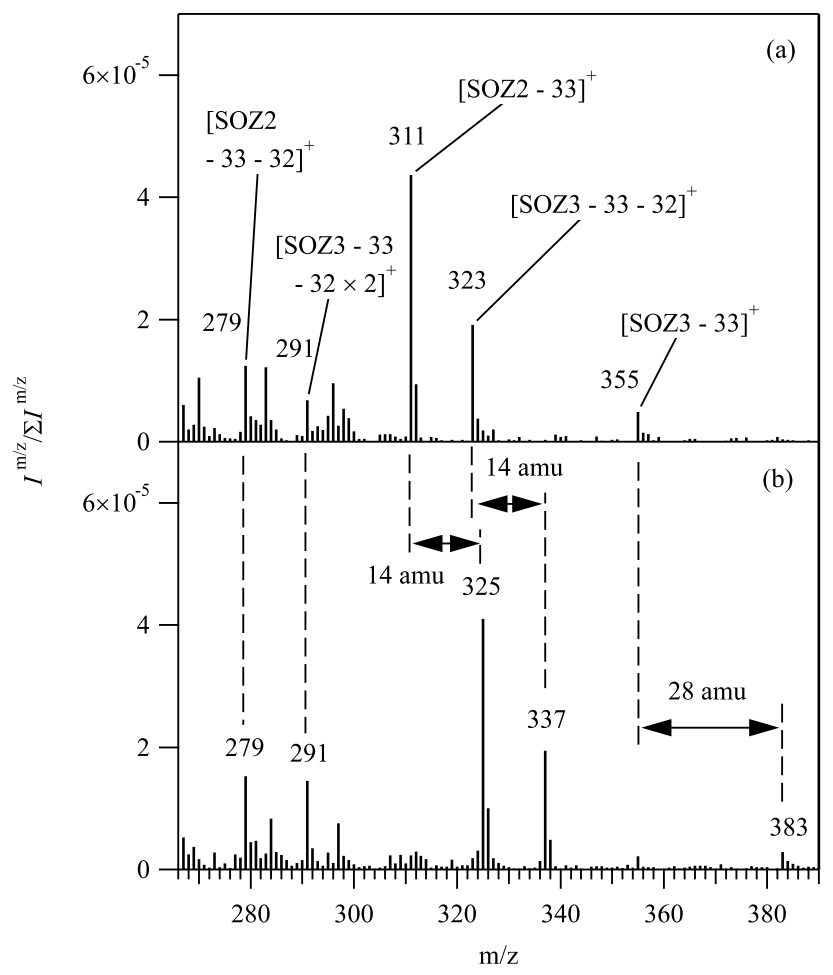

Fig. 5. Mass spectra for $m / z, 270$ through 390 amu after the ozonolysis of (a) methyl oleate and (b) ethyl oleate aerosol particles. The particle mobility diameter prior to ozonolysis is $500 \mathrm{~nm}$. The ozone exposure is $5 \times 10^{-5}$ atm for $6 \mathrm{~s}$. The structures of the SOZ molecules are shown in Fig. 2.

The product mass yields are therefore $67 \mathrm{wt} \%$ remaining in the particle, which is balanced by evaporation of $33 \mathrm{wt} \%$. We infer that HMW products constitute over $95 \%$ of the mass remaining in the particle because LMW products constitute an upper limit of $5 \%$ by volume of the particles, at least according to our previous inference. The evaporated portion of the ozonolysis products may include LMW products (NN, NA, OAME, and AAME) as well as that fraction of the HMW products having relatively higher vapor pressures.

\subsection{Pathways to secondary ozonides}

Formation of SOZ's during MO ozonolysis is supported by the presence of fragment ions at $\mathrm{m} / \mathrm{z} 279,291,311,323$, and 355 (Fig. 5a), which arise from SOZ2 (MW 344) and SOZ3 (MW 388) (cf. Fig. 2). [M-33] of SOZ2 at $\mathrm{m} / \mathrm{z} 311$ forms from the loss of $\mathrm{HO}_{2}$ (MW 33), which is a common fragmentation pathway for electron-impact ionization of SOZ's (Ziemann, 2005). Methanol (MW 32) is eliminated from methyl esters, yielding a peak at $[\mathbf{M}-32]$. The peak at $m / z, 279$ is therefore attributed to $[\mathrm{M}-33-32]$ of SOZ2. By analogy, SOZ3 has peaks at $m / z 355([\mathrm{M}-33])$ and $m / z 323([\mathrm{M}-33-$ 32]). In addition, SOZ3 has a peak at [M-33-32-32] because of the elimination of two methyl-ester groups (cf. SOZ2 and SOZ3 in Fig. 2).

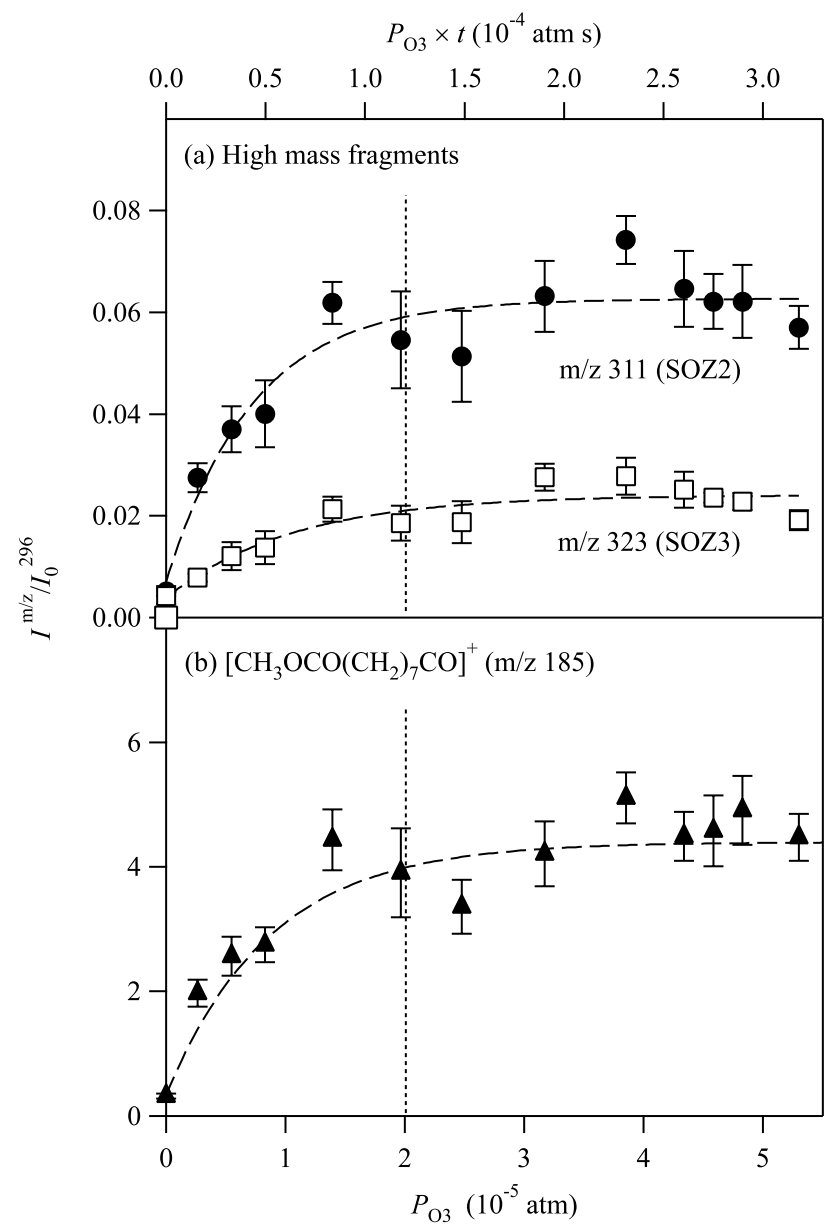

Fig. 6. Appearance of products for increasing ozone partial pressure in the ozonolsyis of pure methyl oleate. (a) Signal intensities $\mathrm{m} / \mathrm{z}$ 311 and 323 of SOZ fragment ions. (b) Signal intensity $\mathrm{m} / \mathrm{z} 185$ of the acylium ion $\left[\mathrm{CH}_{3} \mathrm{OCO}\left(\mathrm{CH}_{2}\right)_{7} \mathrm{CO}\right]^{+}$. The peak intensities are normalized to the intensity of $\mathrm{m} / \mathrm{z}, 296$ prior to ozonolysis. The $\mathrm{O}_{3}$ concentration for which methyl oleate reacts to near completion is shown by the vertical line. Dashed lines are guides to the eye. The particle mobility diameter prior to ozonolysis is $500 \mathrm{~nm}$. The exposure time is $6 \mathrm{~s}$.

The peak assignments of SOZ's are further confirmed by the ozonolysis of aerosol particles of ethyl oleate. The expected peaks at $m / z 279,291,325,337$, and 383 are apparent in Fig. 5b, corresponding to ethyl oleate analogues of SOZ2 and SOZ3 (dubbed SOZ2_EO and SOZ3_EO). The loss of ethanol (MW 46) instead of methanol (MW 32) is observed. Fragment ion peaks of SOZ2_EO occur at $\mathrm{m} / \mathrm{z} 279$ $([\mathrm{M}-33-46])$ and $325([\mathrm{M}-33])$, and those of SOZ3_EO occur at $m / z 291$ ([M-33-46-46]), 337 ([M-33-46]), and 383 ([M-33]).

The ozone-profile concentrations of SOZ2 and SOZ3, reflected in Fig. 6 by the increasing intensities of peaks at $\mathrm{m} / \mathrm{z} 311$ and 323 for higher ozone partial pressure, behave as expected, lending further support to the accuracy of the 
peak assignments. The leveling off of peak intensity above $2.0 \times 10^{-5} \mathrm{~atm} \mathrm{O}_{3}\left(1.5 \times 10^{-4} \mathrm{~atm} \mathrm{~s}^{-1}\right)$ corresponds to the reactive depletion of $\mathrm{MO}$ (Fig. 3), indicating that further ozone exposure does not affect the SOZ yields. The signal intensity at $m / z, 185$ (Fig. 6b), which arises from the acylium ion $\left[\mathrm{CH}_{3} \mathrm{OCO}\left(\mathrm{CH}_{2}\right)_{7} \mathrm{CO}\right]^{+}$, similarly increases and then levels off for higher ozone concentrations. The acylium ion forms by electron-impact ionization of SOZ's and other oxygenated products (Ziemann, 2005).

The formation of SOZ3, a cross ozonide, demonstrates that SCI's have a lifetime sufficiently long to diffuse and react with other molecules. A normal ozonide forms from a single parent molecule, as exemplified by $\mathrm{SOZ} 2$ from SCI1+OAME or SCI2+NN. A cross ozonide, however, requires two parent molecules. For example, the precursors to SOZ3 are SCI2 and OAME, each of which is exclusionary to the formation of the other from a single molecule. Based upon possible molecular combinations, the predicted relative molar yields of SOZ's are SOZ1:SOZ2:SOZ3=1:2:1. This analysis, however, omits any preference towards SCI1 or SCI2 in the cleavage of the primary ozonide and assumes that the reactions of SCI's with NN and OAME are equally favorable. In comparison to the 2:1 prediction, the data instead show that the relative intensities of the SOZ2 peaks compared to those of SOZ3 are 3:1 (Fig. 6a), indicating a correspondingly higher yield of SOZ2, at least for the assumption of similar ionization efficiencies. In a bulk ozonolysis study of MO, the product yields of SOZ1, 2, and 3 are $9.9 \%, 66 \%$, and $13 \%$, respectively, based upon HPLC analysis (Wu et al., 1992). Caging of the SCI/aldehyde pair by solvent molecules leads to a greater yield of the normal ozonide SOZ2 by increasing the effective rate constant of SCI1 with OAME and SCI2 with NN (Loan et al., 1965). The formation of SOZ3 shows that the caging effect is overcome in many reactions, which implies that SCI's diffuse through the matrix prior to reacting with other molecules.

The absence of a change in the relative yield of the cross ozonide compared to the normal ozonide for increasing MO concentration in an inert matrix of dioctyl adipate (DOA) provides further evidence that the caging effect is weak for this system (Fig. 7a). The effectiveness of the caging of the SCI's and the aldehydes formed by the scission of the primary ozonide weakens for increasing solvent polarity (del Rio et al., 1997; Ziemann, 2005). For instance, the normal ozonide from 2-pentene is preferred in the nonpolar solvent pentane because of a strong caging effect (Loan et al., 1965). The relative yields of SOZ2 and SOZ3 are shown in Fig. 7a for an increasing mole fraction of MO in DOA. The yields are calculated from the ratio of the intensities of $\mathrm{m} / \mathrm{z} 311$ for SOZ2 and $\mathrm{m} / \mathrm{z} 323$ for SOZ3 to the initial intensity of $\mathrm{m} / z 296$ for MO. The SOZ yields and their ratio are constant within measurement uncertainty for MO mole fractions ranging from 0.04 to 1 . The constant $\mathrm{SOZ} 3 / \mathrm{SOZ} 2$ ratio (Fig. 7b) suggests that the formation of the normal ozonide SOZ2 via caging is of limited importance in a polar solvent

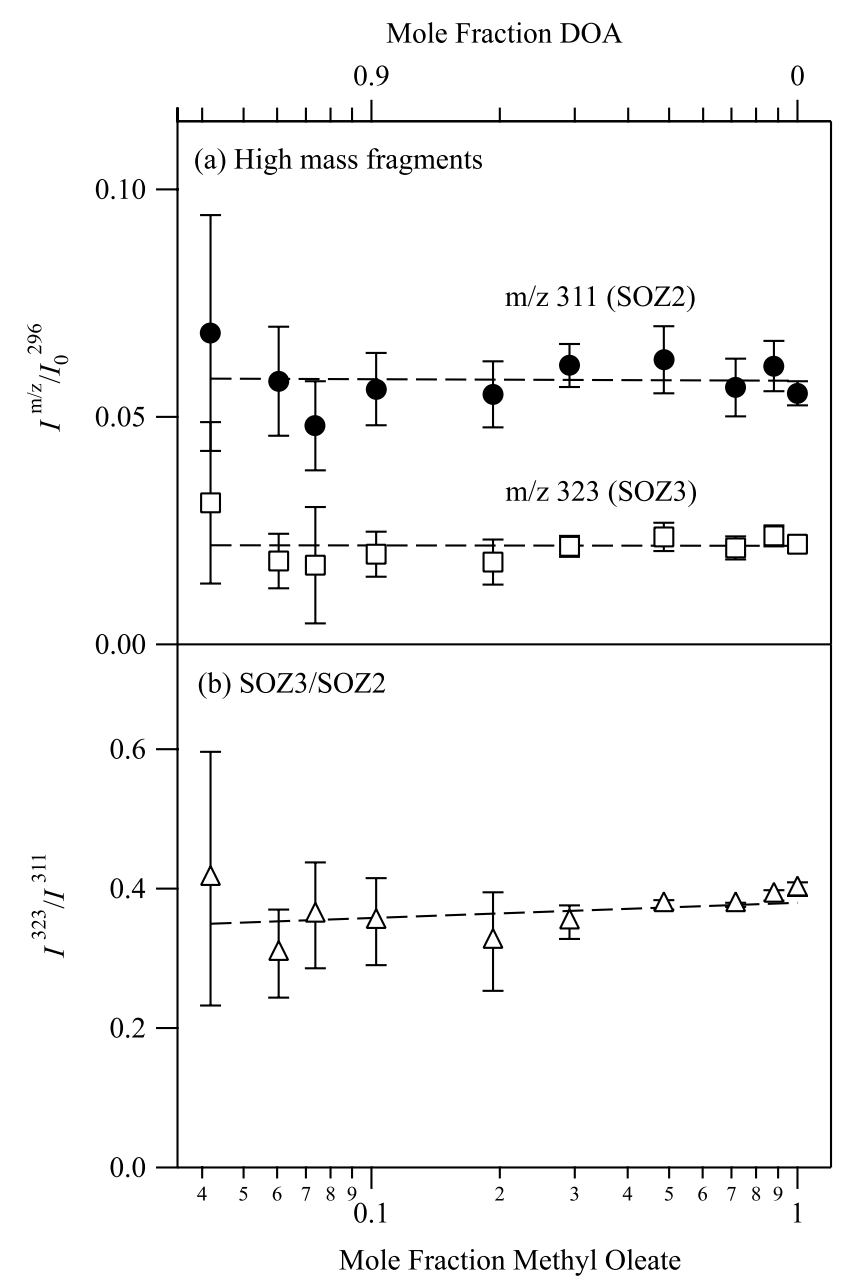

Fig. 7. Signal intensities for increasing mole fraction of methyl oleate in DOA after $\mathrm{O}_{3}$ exposure of $5 \times 10^{-5}$ atm for $6 \mathrm{~s}$. (a) Signal intensities $\mathrm{m} / \mathrm{z} 311$ and 323 of SOZ products normalized to the initial intensity of $\mathrm{m} / z 296$ (i.e., the MO molecular ion). (b) Ratio of the signal intensity of $\mathrm{m} / \mathrm{z}, 323$ to that of $\mathrm{m} / \mathrm{z}, 311$. Dashed lines are guides to the eye. The particle mobility diameter prior to ozonolysis is $500 \mathrm{~nm}$.

of mixed MO and DOA and, moreover, that any changes in this caging effect for changes in the MO/DOA solvent composition are not detectable as variance in the measured product yields. An implication of the experiment is that the yields of SOZ's under diluted conditions are as high as in pure particles. We therefore conclude that potential competing pathways, such as unimolecular rearrangement of diffusing SCI's to carboxylic acids, are not significant.

The detected concentration of SOZ1 (MW 310; [M-33] at $\mathrm{m} / \mathrm{z}$ 267) is low: the peak intensity of $\mathrm{m} / \mathrm{z}, 267$ relative to that of $\mathrm{m} / \mathrm{z} 311$ ([SOZ2-33] $]^{+}$) is 0.07 (Fig. 5)). This finding is consistent with the low product yield reported for bulk ozonolysis (Wu et al., 1992). An additional possibility is that the products of aerosol particles and bulk studies differ: the small system size of the former allows volatile reactants and 


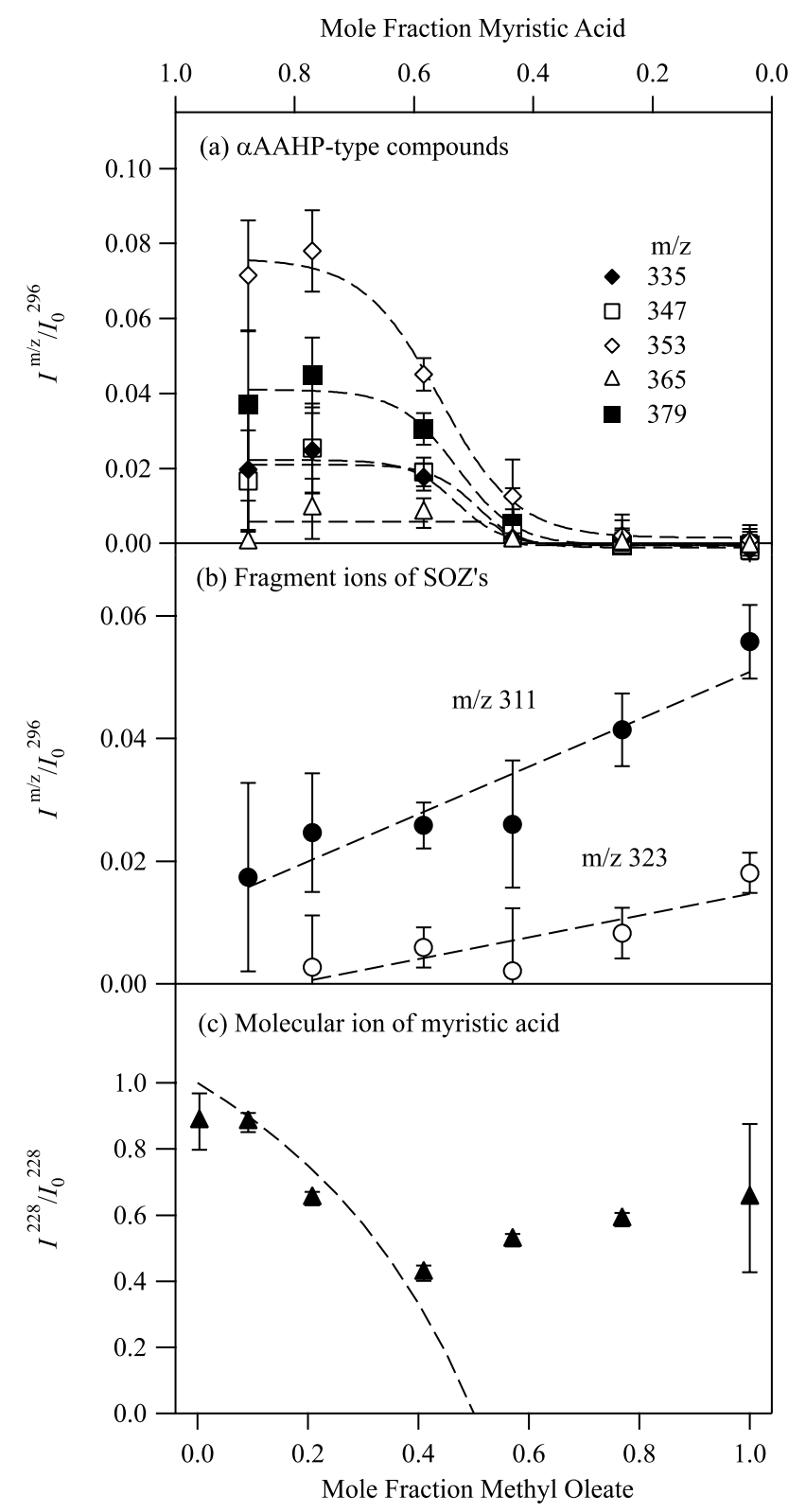

Fig. 8. Signal intensities for increasing mole fraction of methyl oleate in MA after $\mathrm{O}_{3}$ exposure of $5 \times 10^{-5}$ atm for $6 \mathrm{~s}$. (a) Signal intensities $m / z$ 335, 347, 353, 365, and 379 of $\alpha$ AAHP-type compounds normalized to the initial intensity of $\mathrm{m} / \mathrm{z} 296$ (MO molecular ion). (b) Signal intensities $\mathrm{m} / \mathrm{z} 311$ and 323 of SOZ products normalized to the initial intensity of $\mathrm{m} / \mathrm{z}$ 296. (c) Signal intensity $\mathrm{m} / \mathrm{z}$ 228 of the MA molecular ion normalized to its initial intensity. The dashed curve in $c$ shows the calculated ratio $I^{228} / I_{0}^{228}$ for the upper limit that $100 \%$ of SCI's formed by MO ozonolysis reacts with the $-\mathrm{COOH}$ group of MA. Dotted lines are guides to the eye. The particle mobility diameter prior to ozonolysis is $500 \mathrm{~nm}$.

products to evaporate. The absence of carboxylic acid groups in SOZ1 implies a higher volatility for it compared to SOZ2 and SOZ3 (Ziemann, 2005). Moreover, volatilization of NN, which is the precursor to SOZ1, could be important, as sup- ported in studies of oleic acid ozonolysis (Moise and Rudich, 2002; Thornberry and Abbatt, 2004). Although Zahardis et al. (2005) report that SOZ1 forms as an ozonolysis product of oleic acid aerosol particles, Reynolds et al. (2006) do not. Ziemann (2005) suggests that SOZ1 is not detected in aerosol particles because of its high volatility.

\subsection{Pathways to $\alpha$-Acyloxyalkyl-1-Hydroperoxides}

Although Fig. 2 presents a pathway that $\alpha$ AAHP-type compounds could form via the reactions of SCI with the carboxylic acid groups of LMW products, the results shown in Fig. 5 indicate that the pathway to $\alpha$ AAHP-type compounds is in fact insignificant for the case of ozonolysis of pure MO. $[\mathrm{M}-33]^{+}$is a characteristic fragment ion of $\alpha$ AAHP's (Ziemann, 2005). Peak intensities in Fig. 5a are insignificant for $m / z, 293$ of $\alpha$ AAHP1-33, $m / z, 327$ of $\alpha$ AAHP2a -33 or $\alpha$ AAHP $2 b-33$, and $m / z, 371$ of $\alpha$ AAHP3-33. Moreover, BAAP's and AAHAP's, which are also $\alpha$ AAHP-type compounds, have substructures identical to those of $\alpha$ AAHP's and, if present, should contribute peak intensity at the same $m / z$ values. The accuracy of these peak assignments for $\alpha$ AAHP-type compounds is confirmed by analysis of the products formed by the ozonolysis of mixed AAME/MO particles. AAME, which is one of the LMW products of MO ozonolysis, promotes the formation of $\alpha$ AAHP-type compounds (Fig. 2). For an AAME mole fraction of 0.50 prior to ozonolysis, strong peaks appear at $\mathrm{m} / \mathrm{z}, 295,327$, and 371 upon ozonolysis (mass spectra not shown). The intensity of $\mathrm{m} / \mathrm{z} 311$ of SOZ2 also decreases, as expected. The peaks are assigned as $\left[\alpha \mathrm{AAHP} 2 \mathrm{a}, \mathrm{b}-\mathrm{HO}_{2}-\mathrm{CH}_{3} \mathrm{OH}\right]^{+}$for $m / z$ 295, $\left[\alpha \text { AAHP2a,b }-\mathrm{HO}_{2}\right]^{+}$for $m / z$ 327, and $[\alpha$ AAHP3 $\left.-\mathrm{HO}_{2}\right]^{+}$for $m / z$ 371. The strength of the peaks for the mixed AAME/MO particles, combined with the assumption of $100 \%$ yield of $\alpha$ AAHP-type compounds under these conditions, establishes an upper limit of $7 \mathrm{wt} \%$ yield of $\alpha$ AAHPtype compounds for pure MO particles based upon the minimum detection threshold. The absence of $\alpha$ AAHP-type compounds as products in the ozonolysis of pure MO particles is consistent with previous bulk MO ozonolysis studies using ${ }^{1} \mathrm{H}-\mathrm{NMR}$ (Rebrovic, 1992) and HPLC (Nishikawa et al., 1995) for product characterization. In contrast to MO ozonolysis, $\alpha$ AAHP-type compounds are the dominant products in the ozonolysis of oleic acid (Hung et al., 2005; Ziemann, 2005; Zahardis et al., 2006b; Reynolds et al., 2006). This result can be explained by the chemical differences of MO and oleic acid as solvents, namely the SCI-inert ester group of MO compared to the SCI-scavenging carboxylic acid group of oleic acid.

The formation of $\alpha$ AAHP-type compounds during $\mathrm{MO}$ ozonolysis in the presence of carboxylic acids is further investigated by studying product formation in mixed MA/MO aerosol particles (Fig. 8). Myristic acid (MA) is a $\mathrm{C}_{14}$ saturated hydrocarbon terminated by a carboxylic acid group. $\alpha$ AAHP_MA1 (MW 386) and $\alpha$ AAHP_MA2 (MW 430) 
form by the reactions SCI1+MA and SCI2+MA, respectively. For initial mole fractions of MO less than 0.5, strong peak intensities occur at $\mathrm{m} / \mathrm{z} 335,347,353,365$, and 379, corresponding to [ $\alpha$ AAHP_MA1 $\left.-\mathrm{HO}_{2}-\mathrm{H}_{2} \mathrm{O}\right]^{+}$ (e.g., 335=386-51), [ $\alpha$ AAHP_MA2 $-\mathrm{HO}_{2}-\mathrm{CH}_{3} \mathrm{OH}-$ $\left.\mathrm{H}_{2} \mathrm{O}\right]^{+},\left[\alpha \text { AAHP_MA } 1-\mathrm{HO}_{2}\right]^{+},\left[\alpha\right.$ AAHP_MA2 - $\mathrm{HO}_{2}-$ $\left.\mathrm{CH}_{3} \mathrm{OH}\right]^{+}$, and $\left[\alpha \mathrm{AAHP} \_\mathrm{MA} 2-\mathrm{HO}_{2}-\mathrm{H}_{2} \mathrm{O}\right]^{+}$, respectively (Fig. 8a). These structures may also result from the breakdown of AAHAP's and BAAP's of MO and MA during AMS analysis. Figure $8 \mathrm{~b}$ further shows that when $\alpha$ AAHPtype compounds occur in high yield, the yield of SOZ's decreases (Fig. 8b), which can be expected for competitive parallel pathways.

The reactive loss of MA is also observed (Fig. 8c). MA itself does not react with ozone so that its loss is explained by reaction with SCI's. For initial MO mole fractions less than 0.4, the magnitude of the decrease in MA appears fully explained by assuming that $100 \%$ of SCI's formed by MO ozonolysis reacts with the $-\mathrm{COOH}$ group of MA (dashed line in Fig. 8c). The molar product yield of $\alpha$ AAHP-type compounds from $\mathrm{MO}$ is therefore also expected to be nearly $100 \%$, and the SOZ molar product yield could approach $0 \%$. For MO mole fractions greater than 0.4, however, MA does not react completely. Furthermore, its fractional loss decreases slightly in tandem with the decreasing yields of $\alpha$ AAHP-type compounds (Figs. $8 \mathrm{a}$ and c). The implication could be that as the concentration of $\mathrm{C}=\mathrm{O}$ species increases, such as by increased formation of LMW products OAME and $\mathrm{NN}$, and as the concentration of $\mathrm{COOH}$ species concurrently decreases, there may be a crossover in the fate of the SCI's from $\alpha$ AAHP to SOZ pathways for mixed MA/MO particles of increasing $\mathrm{MO}$ mole fraction (Fig. 2). For bulk ozonolysis products of a 1:1 (w/w) mixture of MO/NA, Nishikawa et al. (1995) measure a $89.7 \mathrm{wt} \%$ yield of $\alpha$ AAHP-type compounds. Such a high yield is consistent with the results presented in Figs. 8a and c, although the carboxylic acid used (NA) is different from that used in this study (MA).

The high yield of SOZ's and the absence of $\alpha$ AAHP-type compounds in the ozonolysis of pure MO particles suggest that NA and AAME do not form in high yield. Isomerization of CI's is therefore a minor pathway. Hung et al. (2005) reach the same conclusion for the ozonolysis of oleic acid. The CI's thermalize to form SCI's, which react as shown in Fig. 2 to form the measured products. The present study with $\mathrm{MO}$ provides further evidence that $\mathrm{CI}$ isomerization is a minor pathway by demonstrating that $\alpha$ AAHP-type compounds readily form when - $\mathrm{COOH}$ bonds are made available by preparing mixed AAME/MO or MA/MO. Therefore, if NA or AAME could form from isomerization of CI's in pure MO particles, rapid reaction with available SCI's would take place and $\alpha$ AAHP-type compounds would be observed. CI isomerization is presumably more favored in the gas phase, for which it is widely reported, than in the condensed-phase because of the longer lifetime for collision deactivation in the case of the former.
SCI reactions with carboxylic acid groups are an example of a broader reaction mechanism of SCI's with protic or nucleophilic molecules to form hydroperoxides. For example, ozonolysis of MO particles prepared by nebulization from methanol and without a charcoal scrubber in place leads to a change in the mass spectra (data not shown). Peaks appear at $\mathrm{m} / \mathrm{z} 157$ and 201, which are attributed to the $\left[\mathrm{M}-\mathrm{HO}_{2}\right]^{+}$ions of $\mathrm{CH}_{3}\left(\mathrm{CH}_{2}\right)_{7} \mathrm{CH}(\mathrm{OOH}) \mathrm{OCH}_{3}$ and $\mathrm{CH}_{3} \mathrm{OCO}\left(\mathrm{CH}_{2}\right)_{7} \mathrm{CH}(\mathrm{OOH}) \mathrm{OCH}_{3}$. These alkoxy hydroperoxides form by the reaction between SCI's and residual methanol.

3.5 Pathways to diperoxides, monoperoxide oligomers, and methyl oxo-stearates

The detected high-mass fragments provide no direct evidence for the presence of diperoxides or monoperoxide oligomers (-C-COOC-) (Fig. 5a). For example, DP1, 2, and 3 have molecular weights of $\mathrm{m} / \mathrm{z} 325,360$, and 404, yet no significant intensity is observed at these $\mathrm{m} / \mathrm{z}$ values or at other $\mathrm{m} / \mathrm{z}$ values that might correspond to the loss of methanol, water, or other small fragments during electron-impact ionization. The absence of direct evidence notwithstanding, diperoxides or monoperoxide oligomers could form but could readily decompose at $25^{\circ} \mathrm{C}$ inside the particles or, if not, go undetected in the analysis because of pyrolysis to LMW molecules on the $250^{\circ} \mathrm{C}$ vaporizer surface of the AMS (Leiva et al., 2004; Ziemann, 2005). In this case, the LMW molecules, rather than the diperoxides or monoperoxide oligomers, would be detected by the subsequent electron-impact ionization and quadrupole mass filtering of the AMS. Another possibility is that the DP's may form but volatilize from the particles and therefore go undetected, which is an explanation analogous to that put forward for the absence of SOZ1 in the detected products (Sect. 3.3). Using MS-MS analyses, Reynolds et al. (2006) provide evidence that DP's form in solutions of oleic acid in ethyl acetate. Correspondingly, the MS-MS results do not show evidence for monoperoxide oligomers.

The characteristic peaks of the SCI-derived ketones methyl 9-oxo- and 10-oxo-stearates have at most weak intensity. For instance, a $\left[\mathrm{M}-\mathrm{CH}_{3} \mathrm{OH}\right]^{+}$fragment at $\mathrm{m} / z 280$ for these ketones may be present in Fig. 5 as a product of MO ozonolysis, but its intensity and therefore its corresponding concentration is $10^{4}$ times lower than its analogous peak fragment at $m / z 264$ for pure MO. This report of methyl oxostearates as minor products is consistent with the $2 \%$ or less yield reported for oleic acid ozonolysis (Hearn and Smith, 2004).

In the MA/MO experiments, for increasing MO mole fraction there is a corresponding positive linear trend in the yield of SOZ's and a negative nonlinear trend in the yield of $\alpha$ AAHP-type compounds (Fig. 8). This relationship implies the formation of additional products from the SCI's. Under the assumption that the mechanism shown in Fig. 2 is complete, possible fates of the SCI's include diperoxides, 


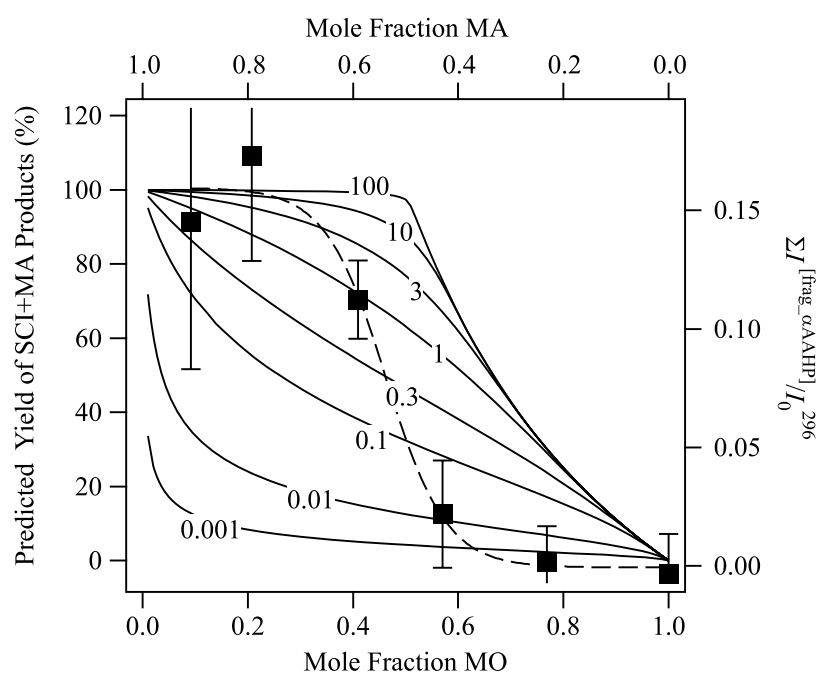

Fig. 9. Predicted and observed yields of $\alpha$ AAHP-type compounds for increasing mole fraction of methyl oleate in MA after $\mathrm{O}_{3}$ exposure of $5 \times 10^{-5}$ atm for $6 \mathrm{~s}$ at room temperature and $0 \%$ relative humidity. Predicted yields (solid lines) are shown for several different ratios of $k_{2}: k_{1}$ (see text). Observed yields (solid squares connected by a dashed guide line) are calculated as the sum of peak intensities at $m / z 335,347,353,365$, and 379 divided by the initial intensity at $m / z, 296$ (cf. Fig. 8a).

monoperoxide oligomers, and the LMW products NA and AAME. Our analysis of the collected mass spectra does not further discriminate among these possibilities.

3.6 Assessment of the relative importance of competing reactions

The relative importance of competing pathways in the ozonolysis of mixed MA/MO particles is assessed using a model. An assumption is made of steady-state concentrations for the SCI's. The modeled reactions are as follows:

$\mathrm{SCI}^{\prime} \mathrm{s}+\{$ LMW aldehydes $\} \stackrel{k_{1}}{\longrightarrow} \mathrm{SOZ}$ 's

$\mathrm{SCI}^{\prime} \mathrm{s}+\mathrm{MA} \stackrel{k_{2}}{\longrightarrow} \alpha \mathrm{AAHP}-$ type compounds

The reaction mechanism omits a pathway for the formation of LMW carboxylic acids (AAME and NA) because the data imply that these products are minor (Sect. 3.2). Possible formation of diperoxides, monoperoxide oligomers, and SCIderived ketones is also not directly modeled (see below).

The yields of $\alpha$ AAHP-type compounds in this competitive kinetics scheme are shown in Fig. 9 as curves corresponding to different assumed ratios $k_{2}: k_{1}$. The superimposed solid squares show the sums of the signal intensities $\mathrm{m} / \mathrm{z} 335,347,353,365$, and 379 , which arise from $\alpha$ AAHPtype compounds. The intensities are scaled to $100 \%$ yield for an MO mole fraction of 0.15 . Comparison of the solid squares to the curves constrains $k_{2}: k_{1}$ between 0.3 and 3 for MO mole fractions less than 0.5 . For higher mole fractions, the apparent decrease in $k_{2}: k_{1}$ may occur because the reaction mechanism of Reactions (R1) and (R2) is incomplete. For example, the formation of diperoxides is second-order in SCI's.

\section{Conclusions and atmospheric implications}

The ozonolysis of methyl oleate in pure and mixed submicron aerosol particles to form high-molecular-weight organic peroxides is investigated. Two secondary ozonides are identified as major HMW ozonolysis products in pure MO particles and in particles of MO diluted in an inert matrix of DOA. $\alpha$-acyloxyalkyl peroxides are the dominant products when MO is ozonolyzed in mixed particles having high concentrations of - $\mathrm{COOH}$ groups (e.g., myristic acid in this study). The reactions of the SCI's for carboxylic groups to form $\alpha$ AAHPtype compounds compete with those of the SCI's for LMW aldehydes to form SOZ's, provided that both types of functionalities are present at significant concentrations. Although the mass spectra do not indicate the presence of diperoxides or monoperoxide oligomer products, their formation is nevertheless not ruled out because pyrolysis or evaporation is possible prior to analysis, and, given the constraints of mass balance, their formation is inferred as plausible. The mass spectra support the formation of SCI-derived ketones but at a yield much less than $1 \%$.

Although atmospheric particles are of much greater chemical heterogeneity than those of the model particles in our study, certain common elements remain, and the SCI reactivity observed in this study suggests possible reaction pathways of ozone with unsaturated organic molecules to yield HMW peroxides in atmospheric aerosol particles. Mainly, the intermolecular reaction of stabilized Criegee intermediates with carboxylic acid and other protic or nucleophilic moieties may compete with the formation of secondary ozonides and other products. Furthermore, in regard to SCI reactivity, both the unreacted and the reacted model particles of our study have important chemical similarities to atmospheric particles (Table 2). The concentration of double bonds in atmospheric particles ranges from 12 to 28 mole percent, which is several times greater than the 0.2 to $5.4 \%$ of the unreacted model particles. The concentrations of $\mathrm{C}=\mathrm{O}$ and $\mathrm{C}-\mathrm{OH}$ in atmospheric particles ranges from 1 to $8 \%$ to 1 to $5 \%$, respectively. Carboxyl acids $(-\mathrm{COOH})$ may account for a significant portion of these $\mathrm{C}=\mathrm{O}$ and $\mathrm{C}-\mathrm{OH}$ groups. The mixed MA/MO particles have comparable - $\mathrm{COOH}$ concentrations. For example, the concentration is $2.1 \%$ for MA/MO particles of 0.40 mole fraction. Notably, $\alpha$ AAHP-type compounds become important HMW products for mole fractions of 0.40 and greater. An additional chemical factor is particle liquid water content, which is nearly zero in the experiments of this study at $0 \%$ relative humidity whereas it can be 
Table 2. Chemical functional groups present in atmospheric particles collected in East Asia compared to those present prior to ozonolysis in the model aerosol particles of this study. Values are shown in mole percent. In the last column, the alkene ozone exposure is given. For the ambient aerosol, $50 \mathrm{ppb} \mathrm{O}_{3}$ is assumed. ${ }^{\mathrm{a}}$ Ranges for ten samples presented by Maria et al. (2003) based upon infrared analysis. ${ }^{\mathrm{b}}$ Lower limit of methyl oleate concentration of this study. ${ }^{\mathrm{c}}$ Values in parentheses are the fractions of the carbonyl bonds in carboxylic acid groups.

\begin{tabular}{lcccc}
\hline & $\begin{array}{c}{[\mathrm{C}=\mathrm{O}]} \\
(\%)\end{array}$ & $\begin{array}{c}{[\mathrm{C}-\mathrm{OH}]} \\
(\%)\end{array}$ & $\begin{array}{c}{[\text { Alkene }]} \\
(\%)\end{array}$ & $\begin{array}{c}{\left[\text { Alkene } \times P_{\mathrm{O} 3}\right.} \\
\left(10^{-9} \text { atm }\right)\end{array}$ \\
\hline ambient aerosol & $1-8^{\mathrm{a}}$ & $1-5^{\mathrm{a}}$ & $12-28^{\mathrm{a}}$ & $6-14^{\mathrm{a}}$ \\
methyl oleate & $2.7(0)^{\mathrm{c}}$ & 0 & 5.4 & $3.2 \times 10^{3}$ \\
4 mol\% methyl oleate in DOA & $2.3(0)^{\mathrm{c}}$ & 0 & 0.2 & $1.3 \times 10^{2}$ \\
40 mol\% methyl oleate in myristic acid & $3.2(2.1)^{\mathrm{c}}$ & 2.1 & 0.5 & $3.2 \times 10^{2}$ \\
\hline
\end{tabular}

substantial in atmospheric particles (Dick et al., 1996). SCI's can react with water, having the effect of favoring LMW over HMW products. Pryer et al. (1991), for example, report that $\mathrm{H}_{2} \mathrm{O}_{2}$ and aldehydes form for MO reacted in aqueous emulsions: the $\mathrm{SCI}+\mathrm{H}_{2} \mathrm{O}$ yields a hydroxy hydroperoxide that hydrolyzes to form the observed products.

Ozone concentration and particle exposure time must also be considered in regard to extending the laboratory results to possible processes in the atmosphere. The ozone mixing ratio in the troposphere of 10 to $100 \mathrm{ppb}$ is approximately 1000 times less than that of 50-70 ppm employed in many parts of this study (Figs. 5 and 7-9). Slower ozonolysis rates in atmospheric particles could suggest that steady-state SCI concentrations are lower than in the model particles, which would imply that reactions second-order in SCI, such as the formation of diperoxides, are less favored. The formation of $\alpha$ AAHP-type compounds, secondary ozonides, and monoperoxide oligomers, however, remains favorable provided that abundant $-\mathrm{COOH},-\mathrm{C}-\mathrm{OH}$, and $-\mathrm{C}=\mathrm{O}$ functionalities are present in atmospheric particles. Based upon analysis offered above, $\alpha$ AAHP-type compounds could become favored to secondary ozonides and monoperoxide oligomers once the ratio of concentrations of $-\mathrm{COOH}$ to $-\mathrm{C}=\mathrm{O}$ exceeds a critical ratio. A related implication of these reaction pathways is that the direct ozonolysis of unsaturated organic molecules can lead to the indirect processing of saturated organic molecules having carboxylic, carbonyl, and hydroxyl groups.

The residence time of particles in the atmosphere, which is one to two weeks, is much longer than the $6 \mathrm{~s}$ of most of our experiments, which has important implications for the steady-state concentration of possible HMW peroxides in atmospheric particles. Over a time period of days, some HMW peroxides could react further, including lysing into LMW products or alternatively further oligomerization to higher molecular weights. For instance, diperoxides thermally decompose to form LMW aldehydes (Leiva et al., 2004). Peroxides also react by photochemical and acidcatalyzed aqueous pathways (Ziemann, 2005). SOZ's undergo acid-catalyzed hydrolysis to form LMW aldehydes and carboxylic acids (Bernatek and Ledaal, 1960). Some reactions, however, can also increase MW. For example, as a result of thermal decomposition, SOZ's and diperoxides can initiate chain oligomerization by free-radical pathways (Ewing et al., 1989; Rimmer and Ebdon, 1995).

The results of this study inform on the factors affecting the relative importance of several reaction pathways that could yield HMW peroxides from the reactions of ozone with unsaturated organic molecules in atmospheric particles. Future investigations to further advance these results should focus on the chemical characteristics of atmospheric particles, such as the partitioning of organic molecules among phases (Griffin et al., 2003), the chemical morphology of particles (Katrib et al., 2005a), and the product yields affected by increased reaction times and lower ozone concentrations. Further evaluation focusing on volatilization, which may be affected by competing reaction pathways, is also important to better understand the budget of organic aerosol particles in the atmosphere (Molina et al., 2004).

\section{Appendix A}

\section{Derivation of Eq. (1)}

The weight percent of $\mathrm{MO}\left(w_{\mathrm{MO}}\right)$ is related to the relative contribution of $m / z 296$ of the MO molecular ion to the mass spectrum, as follows. The signal intensity $\mathrm{m} / \mathrm{z}$ of mixed particles $\left(I_{\text {mix }}^{m / z}\right)$ is the sum of the signal intensities from molecules of methyl oleate $\left(I_{\mathrm{MO} / \text { mix }}^{m / z}\right)$ and other molecules in the ma$\operatorname{trix}\left(I_{\text {matrix } / \text { mix }}^{m / z}\right): I_{\text {mix }}^{m / z}=I_{\mathrm{MO} / \text { mix }}^{m / z}+I_{\text {matrix } / \text { mix }}^{m / z}$. This relationship extends to the sum of intensities across $m / z \quad 0$ to 390 , omitting $m / z$ values of air beams (e.g., $m / z 28$ ):

$$
\sum_{m / z} I_{\mathrm{mix}}^{m / z}=\sum_{m / z} I_{\mathrm{MO} / \mathrm{mix}}^{m / z}+\sum_{m / z} I_{\mathrm{matrix} / \mathrm{mix}}^{m / z}
$$

Under the assumption that all signals of a fragmentation pattern lie within the AMS measurement domain of $m / z \quad 0$ to 390 , the sum of AMS signal intensities are proportional to 
mass (Katrib et al., 2004). Therefore, an RIE-weighted mixing rule holds that:

$$
\left(\sum_{m / z} I_{\mathrm{MO} / \mathrm{mix}}^{m / z} / R I E_{\mathrm{MO}}\right):\left(\sum_{m / z} I_{\text {matrix } / \mathrm{mix}}^{m / z} / R I E_{\mathrm{mat}}\right)=w_{\mathrm{MO}}: 100-w_{\mathrm{MO}}
$$

Rearrangement of this equation leads to:

$$
\sum_{m / z} I_{\text {matrix } / \operatorname{mix}}^{m / z}=\frac{\left(100-w_{\mathrm{MO}}\right) R I E_{\text {matrix }}}{w_{\mathrm{MO}} R I E_{\mathrm{MO}}} \sum_{m / z} I_{\mathrm{MO} / \mathrm{mix}}^{m / z}
$$

Substituting Eq. (A3) into Eq. (A1), we obtain:

$$
\begin{aligned}
& \sum_{m / z} I_{\text {mix }}^{m / z}= \\
& \quad \frac{w_{\mathrm{MO}} R I E_{\mathrm{MO}}+\left(100-w_{\mathrm{MO}}\right) R I E_{\text {matrix }}}{w_{\mathrm{MO}} R I E_{\mathrm{MO}}} \sum_{m / z} I_{\mathrm{MO} / \mathrm{mix}}^{m / z}
\end{aligned}
$$

which upon rearrangement leads to:

$$
\begin{aligned}
& I_{\mathrm{mix}}^{296} / \sum_{m / z} I_{\mathrm{mix}}^{m / z}= \\
& \quad \frac{w_{\mathrm{MO}} R I E_{\mathrm{MO}}}{w_{\mathrm{MO}} R I E_{\mathrm{MO}}+\left(100-w_{\mathrm{MO}}\right) R I E_{\text {matrix }}}\left(I_{\text {mix }}^{296} / \sum_{m / z} I_{\mathrm{MO} / \mathrm{mix}}^{m / z}\right)
\end{aligned}
$$

The matrix substances have negligible intensities at $m / z$ 296, which allows the accurate approximation $I_{\mathrm{mix}}^{296} / \sum_{m / z} I_{\mathrm{MO} / \text { mix }}^{m / z} \approx I_{\mathrm{MO}}^{296} / \sum_{m / z} I_{\mathrm{MO}}^{m / z} . \quad$ The right-hand quantity is a constant determined in a separate AMS measurement using pure MO particles. This substitution yields:

$$
\begin{aligned}
& I_{\mathrm{mix}}^{296} / \sum_{m / z} I_{\mathrm{mix}}^{m / z}= \\
& \quad \frac{w_{\mathrm{MO}} R I E_{\mathrm{MO}}}{w_{\mathrm{MO}} R I E_{\mathrm{MO}}+\left(100-w_{\mathrm{MO}}\right) R I E_{\text {matrix }}}\left(I_{\mathrm{MO}}^{296} / \sum_{m / z} I_{\mathrm{MO}}^{m / z}\right)
\end{aligned}
$$

Rearrangement of Eq. (A6) yields Eq. (1):

$$
w_{\mathrm{MO}}=\frac{100 R I E_{\text {matrix }}\left(I_{\text {mix }}^{296} / \sum_{m / z} I_{\text {mix }}^{m / z}\right)}{R I E_{\mathrm{MO}}\left(I_{\mathrm{MO}}^{296} / \sum_{m / z} I_{\mathrm{MO}}^{m / z}\right)+\left(R I E_{\text {matrix }}-R I E_{\mathrm{MO}}\right)\left(I_{\text {mix }}^{296} / \sum_{m / z} I_{\text {mix }}^{m / z}\right)}
$$

Acknowledgements. We thank J. Slowik, P. Davidovits, M. Canagaratna, M. Norway, and A. Trimborn for the cooperation in the validation of the AMS measurement. This material is based upon work supported by the National Science Foundation under Grants ATM-0215357 and ATM-0513463. Any opinions, findings, and conclusions or recommendations expressed in this material are those of the authors and do not necessarily reflect the views of the National Science Foundation.

Edited by: R. Volkamer

\section{References}

Asad, A., Mmereki, B. T., and Donaldson, D. J.: Enhanced uptake of water by oxidatively processed oleic acid, Atmos. Chem. Phys., 4, 2083-2089, 2004,

http://www.atmos-chem-phys.net/4/2083/2004/.

Atkinson, R. and Arey, J.: Atmospheric degradation of volatile organic compounds, Chem. Rev., 103, 4605-4638, 2003.

Bailey, P. S.: Ozonation In Organic Chemistry, London, Academic Press, 1978.

Bernatek, E. and Ledaal, T.: Solvolysis of ozonides, Tetrahedron Lett., 26, 30-34, 1960.

Bertram, A. K., Ivanov, A. V., Hunter, M., Molina, L. T., and Molina, M. J.: The reaction probability of $\mathrm{OH}$ on organic surfaces of tropospheric interest, J. Phys. Chem. A, 105, 9415-9421, 2001.

Broekhuizen, K. E., Thornberry, T., Kumar, P. P., and Abbatt, J. P. D.: Formation of cloud condensation nuclei by oxidative processing: Unsaturated fatty acids, J. Geophys. Res., 109, D24206, doi:10.1029/2004JD005298, 2004.

DeCarlo, P. F., Slowik, J. G., Worsnop, D. R., Davidovits, P., and Jimenez, J. L.: Particle morphology and density characterization by combined mobility and aerodynamic diameter measurements. Part 1: Theory, Aerosol Sci. Technol., 38, 1185-1205, 2004.

del Rio, E., Aplincourt, P., and Ruiz-López, M. F.: Solvent effects on ozonolysis reaction intermediates, Chem. Phys. Lett., 280, 444-450, 1997.

Dick, W. D., Saxena, P., and McMurry, P. H.: Estimation of water uptake by organic compounds in submicron aerosols measured during the Southeastern Aerosol and Visibility Study, J. Geophys. Res., 105, 1471-1479, 2000.

Docherty, K. S. and Ziemann, P. J.: Reaction of oleic acid particles with $\mathrm{NO}_{3}$ radicals: Products, mechanism, and implications for radical-initiated organic aerosol oxidation, J. Phys. Chem. A, 110, 3567-3577, 2006.

Eliason, T. L., Gilman, J. B., and Vaida, V.: Oxidation of organic films relevant to atmospheric aerosols, Atmos. Environ. 38, 1367-1378, 2004.

Ewing, J. C., Cosgrove, J. P., Giamalva, D. H., Church, D. F., and Pryor, W. A.: Autoxidation of methyl linoleate initiated by the ozonide of allylbenzene, Lipids, 24, 609-615, 1989.

Gao, S., Keywood, M., Ng, N. L., Surratt, J., Varutbangkul, V., Bahreini, R., Flagan, R. C., and Seinfeld, J. H.: Low-molecularweight and oligomeric components in secondary organic aerosol from the ozonolysis of cycloalkenes and $\alpha$-pinene, J. Phys. Chem. A, 108, 10 147-10 164, 2004.

Griffin, R. J., Cocker III, D. R., Flagan, R. C., and Seinfeld, J. H.: Organic aerosol formation from the oxidation of biogenic hydrocarbons, J. Geophys. Res., 104, 3555-3567, 1999.

Griffin, R. J., Nguyen, K., Dabdub, D., and Seinfeld, J. H.: A coupled hydrophobic-hydrophilic model for predicting secondary organic aerosol formation, J. Atmos. Chem., 44, 171-190, 2003.

Hearn, J. D., and Smith, G. D.: Kinetics and Product Studies for Ozonolysis Reactions of Organic Particles Using Aerosol CIMS, J. Phys. Chem. A, 108, 10 019-10 029, 2004.

Hearn, J. D., Lovett, A. J., and Smith, G. D.: Ozonolysis of oleic acid particles: Evidence for a surface reaction and secondary reactions involving Criegee intermediates, Phys. Chem. Chem. Phys., 7, 501-511, 2005.

Hearn, J. D. and Smith, G. D.: Measuring rates of reaction in 
supercooled organic particles with implications for atmospheric aerosol, Phys. Chem. Chem. Phys., 7, 2549-2551, 2005.

Hung, H. M., Katrib, Y., and Martin, S. T.: Products and mechanisms of the reaction of oleic acid with ozone and nitrate radical, J. Phys. Chem. A, 109, 4517-4530, 2005.

Iinuma, Y., Böge, O., Gnauk, T., and Herrmann, H.: Aerosolchamber study of the $\alpha$-pinene $/ \mathrm{O}_{3}$ reaction: Influence of particle acidity on aerosol yields and products, Atmos. Environ., 38, 761-773, 2004.

Jang, M., Czoschke, N. M., Lee, S., and Kamens, R. M.: Heterogeneous atmospheric aerosol production by acid-catalyzed particule-phase reactions, Nature, 298, 814-817, 2002.

Jayne, J. T., Leard, D. C., Zhang, X., Davidovits, P., Smith, K. A., Kolb, C. E., and Worsnop, D. R.: Development of an aerosol mass spectrometer for size and composition analysis of submicron particles, Aerosol. Sci. Technol., 33, 49-70, 2000.

Jimenez, J. L., Jayne, J. T., Shi, Q., Kolb, C. E., Worsnop, D. R., Yourshaw, I., Seinfeld, J. H., Flagan, R. C., Zhang, X., Smith, K. A., Morris, J. W., and Davidovits, P.: Ambient aerosol sampling using the Aerodyne Aerosol Mass Spectrometer, J. Geophys. Res., 108, 8425, doi:10.1029/2001JD001213, 2003.

Kalberer, M., Paulsen, D., Sax, M., Steinbacher, M., Dommen, J., Prevot, A. S. H., Fisseha, R.,Weingartner, E., Frankevich, V., Zenobi, R., and Baltensperger, U.: Identification of polymers as major components of atmospheric organic aerosols, Science, 303, 1659-1662, 2004.

Kanakidou, M., Seinfeld, J. H., Pandis, S. N., Barnes, I., Dentener, F. J., Facchini, M. C., Van Dingenen, R., Ervens, B., Nenes, A., Nielsen, C. J., Swietlicki, E., Putaud, J. P., Balkanski, Y., Fuzzi, S., Horth, J., Moortgat, G. K., Winterhalter, R., Myhre, C. E. L., Tsigaridis, K., Vignati, E., Stephanou, E. G., and Wilson, J.: Organic aerosol and global climate modelling: A review, Atmos. Chem. Phys., 5, 1053-1123, 2005,

http://www.atmos-chem-phys.net/5/1053/2005/.

Katrib, Y., Martin, S. T., Hung, H.-M., Rudich, Y., Zhang, H., Slowik, J. G., Davidovits, P., Jayne, J. T., and Worsnop, D. R.: Products and mechanisms of ozone reactions with oleic acid for aerosol particles having core-shell morphologies, J. Phys. Chem. A, 108, 6686-6695, 2004.

Katrib, Y., Biskos, G., Buseck, P. R., Davidovits, P., Jayne, J. T., Mochida, M., Wise, M. E., Worsnop, D. R., and Martin, S. T.: Ozonolysis of mixed oleic-acid/stearic-acid particles: Reaction kinetics and chemical morphology, J. Phys. Chem. A, 109, 10910-10919, 2005a.

Katrib, Y., Martin, S. T., Rudich, Y., Davidovits, P., Jayne, J. T., and Worsnop, D. R.: Density changes of aerosol particles as a result of chemical reaction, Atmos. Chem. Phys., 5, 275-291, 2005 b.

Knopf, D. A., Anthony, L. M., and Bertram, A. K.: Reactive uptake of $\mathrm{O}_{3}$ by multicomponent and multiphase mixtures containing oleic acid, J. Phys. Chem. A, 109, 5579-5589, 2005.

Leiva, L. C., Jorge, N. L., Romero, J. M., Cafferata, L. F. R., and Vara, M. E. G.: Kinetics and mechanism of the thermal decomposition reaction of acetone cyclic diperoxide in methyl tert-butyl ether solution, Int. J. Chem. Kinet., 36, 302-307, 2004.

Loan, L. D., Murray, R. W., and Story, P. R.: The mechanism of ozonolysis. Formation of cross ozonides, J. Am. Chem. Soc., 87, 737-741, 1965.

Maria, S. F., Russell, L. M., Turpin, B. J., Porcja, R. J., Campos, T. L., Weber, R. J., and Huebert, B. J.: Source signa- tures of carbon monoxide and organic functional groups in Asian Pacific Regional Aerosol Characterization Experiment (ACEAsia) submicron aerosol types, J. Geophys. Res., 108, 8637, doi:10.1029/2003JD003703, 2003.

McLafferty, F. W. and Tureček, F.: Interpretation of Mass Spectra., Mill Valley, Calif., University Science Books, 1993.

Moise, T. and Rudich, Y.: Reactive uptake of ozone by aerosolassociated unsaturated fatty acids: Kinetics, mechanism, and products, J. Phys. Chem. A, 106, 6469-6476, 2002.

Morris, J. W., Davidovits, P., Jayne, J. T., Jimenez, J. L., Shi, Q., Kolb, C. E., Worsnop, D. R., Barney, W. S., and Cass, G.: Kinetics of submicron oleic acid aerosols with ozone: A novel aerosol mass spectrometric technique, Geophys. Res. Lett., 29, 1357, doi:10.1029/2002GL014692, 2002.

Nishikawa, N., Yamada, K., Matsutani, S., Higo, M., Kigawa, H., and Inagaki, T.: Structures of ozonolysis products of methyl oleate obtained in a carboxylic acid medium, J. Am. Oil Chem. Soc., 72, 735-740, 1995.

Paulson, S. E. and Orlando, J. J.: The reactions of ozone with alkenes: An important source of $\mathrm{HO}_{\mathrm{x}}$ in the boundary layer, Geophys. Res. Lett., 23, 3727-3730, 1996.

Pryor, W. A., Das, B., and Church, D. F.: The ozonation of unsaturated fatty acids: Aldehydes and hydrogen peroxide as products and possible mediators of ozone toxicity, Chem. Res. Toxicol., 4, 341-348, 1991.

Rebrovic, L.: The peroxidic species generated by ozonolysis of oleic acid or methyl oleate in a carboxylic acid medium, J. Am. Oil Chem. Soc., 69, 159-165, 1992.

Reynolds, J. C., Last, D. J., McGillen, M., Nijs, A., Horn, A. B., Percival, C., Carpenter, L. J., Lewis, A. C.: Structural analysis of oligomeric molecules formed from the reaction products of oleic acid ozonolysis, Environ. Sci. Technol. (now an ASAP article with ES\&T), 2006.

Rimmer, S. and Ebdon, J. R.: Radical polymerizations initiated by novel low molecular weight and polymeric cyclic diperoxides: Synthesis of poly(methyl methacrylate), polystyrene, and poly(styrene-b-methyl methacrylate), Macromol. Rep., A32 (Suppls. 5 and 6), 831-841, 1995.

Rudich, Y.: Laboratory perspectives on the chemical transformations of organic matter in atmospheric particles, Chem. Rev., 103, 5097-5124, 2003.

Smith, G. D., Woods, E., DeForest, C. L., Baer, T., and Miller, R. E.: Reactive uptake of ozone by oleic acid aerosol particles: Application of single-particle mass spectrometry to heterogeneous reaction kinetics, J. Phys. Chem. A, 106, 8085-8095, 2002.

Smith, G. D., Woods, E., Baer, T., and Miller, R. E.: Aerosol uptake described by numerical solution of the diffusion - reaction equations in the particle, J. Phys. Chem. A, 107, 9582-9587, 2003.

Thornberry, T. and Abbatt, J. P. D.: Heterogeneous reaction of ozone with liquid unsaturated fatty acids: Detailed kinetics and gas-phase product studies, Phys. Chem. Chem. Phys., 6, 84-93, 2004.

Tolocka, M. P., Jang, M., Ginter, J. M., Cox, F. J., Kamens, R. M., and Johnston, M. V.: Formation of oligomers in secondary organic aerosol., Environ. Sci. Technol., 38, 1428-1434, 2004.

Wu, M., Church, D. F., Mahier, T. J., Barker, S. A., and Pryor, W. A.: Separation and spectral data of the six isomeric ozonides from methyl oleate, Lipids, 27, 129-135, 1992.

Zahardis, J., LaFranchi, B. W., and Petrucci, G. A.: Photoelec- 
tron resonance capture ionization-aerosol mass spectrometry of the ozonolysis products of oleic acid particles: Direct measure of higher molecular weight oxygenates, J. Geophys. Res., 110, D08307, doi:10.1029/2004JD005336, 2005.

Zahardis, J., LaFranchi, B. W., and Petrucci, G. A.: The heterogeneous reaction of particle-phase methyl esters and ozone elucidation by photoelectron resonance capture ionization: Direct products of ozonolysis and secondary reactions leading to the formation of ketones, Int. J. Mass Spectrom., 253, 38-47, 2006 a.

Zahardis, J., LaFranchi, B. W., and Petrucci, G. A.: Direct observation of polymerization in the oleic acid-ozone heterogeneous reaction system by photoelectron resonance capture ionization aerosol mass spectrometry, Atmos. Environ., 40, 1661-1670, $2006 b$.
Zappoli, S., Andracchio, A., Fuzzi, S., Facchini, M. C., Gelencsér, A., Kiss, G., Krivácsy, Z., Molnár, Á., Mészáros, E., Hansson, H.-C., Rosman, K., and Zebühr, Y.: Inorganic, organic and macromolecular components of fine aerosol in different areas of Europe in relation to their water solubility, Atmos. Environ., 33, 2733-2743, 1999.

Ziemann, P. J.: Aerosol products, mechanisms, and kinetics of heterogeneous reactions of ozone with oleic acid in pure and mixed particles, Faraday Discuss., 130, 469-490, 2005. 